\title{
Thyroid Hormone Acts Locally to Increase Neurogenesis, Neuronal Differentiation, and Dendritic Arbor Elaboration in the Tadpole Visual System
}

\author{
Christopher K. Thompson and Hollis T. Cline \\ Department of Molecular and Cellular Neuroscience and The Dorris Neuroscience Center, The Scripps Research Institute, La Jolla, California 92039
}

\begin{abstract}
Thyroid hormone $(\mathrm{TH})$ regulates many cellular events underlying perinatal brain development in vertebrates. Whether and how $\mathrm{TH}$ regulates brain development when neural circuits are first forming is less clear. Furthermore, although the molecular mechanisms that impose spatiotemporal constraints on TH action in the brain have been described, the effects of local TH signaling are poorly understood. We determined the effects of manipulating TH signaling on development of the optic tectum in stage 46-49 Xenopus laevis tadpoles. Global TH treatment caused large-scale morphological effects in tadpoles, including changes in brain morphology and increased tectal cell proliferation. Either increasing or decreasing endogenous TH signaling in tectum, by combining targeted DIO3 knockdown and methimazole, led to corresponding changes in tectal cell proliferation. Local increases in TH, accomplished by injecting suspensions of tri-iodothyronine $\left(\mathrm{T}_{3}\right)$ in coconut oil into the midbrain ventricle or into the eye, selectively increased tectal or retinal cell proliferation, respectively. In vivo time-lapse imaging demonstrated that local TH first increased tectal progenitor cell proliferation, expanding the progenitor pool, and subsequently increased neuronal differentiation. Local $\mathrm{T}_{3}$ also dramatically increased dendritic arbor growth in neurons that had already reached a growth plateau. The time-lapse data indicate that the same cells are differentially sensitive to $\mathrm{T}_{3}$ at different time points. Finally, TH increased expression of genes pertaining to proliferation and neuronal differentiation. These experiments indicate that endogenous TH locally regulates neurogenesis at developmental stages relevant to circuit assembly by affecting cell proliferation and differentiation and by acting on neurons to increase dendritic arbor elaboration.
\end{abstract}

Key words: dendrite development; in vivo imaging; neural progenitor cell; neurogenesis; retinotectal; thyroxine

Significance Statement

Thyroid hormone $(\mathrm{TH})$ is a critical regulator of perinatal brain development in vertebrates. Abnormal TH signaling in early pregnancy is associated with significant cognitive deficits in humans; however, it is difficult to probe the function of TH in early brain development in mammals because of the inaccessibility of the fetal brain in the uterine environment and the challenge of disambiguating maternal versus fetal contributions of TH. The external development of tadpoles allows manipulation and direct observation of the molecular and cellular mechanisms underlying TH's effects on brain development in ways not possible in mammals. We find that endogenous TH locally regulates neurogenesis at developmental stages relevant to circuit assembly by affecting neural progenitor cell proliferation and differentiation and by acting on neurons to enhance dendritic arbor elaboration.

\section{Introduction}

Thyroid hormone $(\mathrm{TH})$ regulates neurogenesis during perinatal brain development in mammals (Eayrs and Taylor, 1951; Eayrs,

Received Nov. 17, 2015; revised July 22, 2016; accepted Aug. 1, 2016.

Author contributions: C.K.T. and H.T.C. designed research; C.K.T. performed research; C.K.T. analyzed data; C.K.T. and H.T.C. wrote the paper.

This work was supported by grants from the National Institutes of Health (EY011261 and P30 EY019005 to H.T.C. and K99ES022992 to C.K.T.), an endowment from the Hahn Family Foundation to H.T.C., and a California Institute of Regenerative Medicine fellowship to C.K.T. We thank Dr. Robert Denver and members of the Cline laboratory for comments and discussion on this manuscript.

Correspondence should be addressed to Hollis T. Cline, The Dorris Neuroscience Center, The Scripps Research Institute, 10550 North Torrey Pines Road, La Jolla, CA 92039. E-mail: cline@scripps.edu.
1955; Legrand, 1967; Nicholson and Altman, 1972a,b; Denver et al., 1999; Anderson, 2001; Zoeller and Rovet, 2004; Bernal, 2007; Mohan et al., 2012; Wang et al., 2014), but the effects of TH during earlier stages of brain development are unclear. It is difficult to test the effects of TH on early brain development in mammals because of the inaccessibility of the fetal brain and the inability to disambiguate the maternal versus fetal contributions of TH. By contrast, the external development of tadpoles allows manipulation and direct observation of TH's effects on cell pro- 

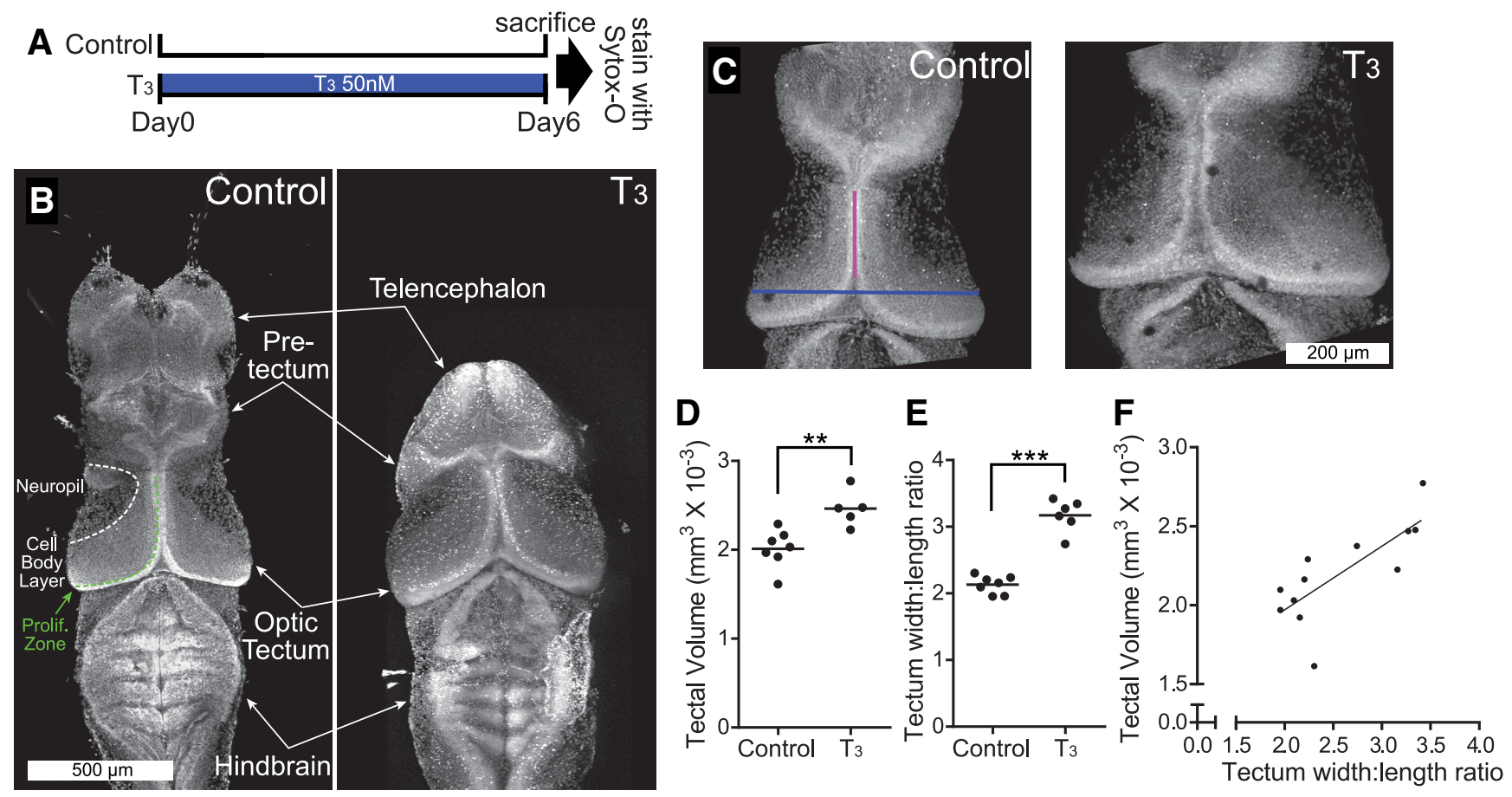

Figure 1. $\mathrm{T}_{3}$ changes brain morphology. $A$, Protocol for $\mathrm{T}_{3}$ treatment. Stage 47 tadpoles were split into two groups: control bath and $\mathrm{T}_{3}$ bath $(50 \mathrm{~nm})$. All animals were killed after $6 \mathrm{~d}$, brains were stained with Sytox-0 to label nuclei, and imaged on a confocal microscope. Prolif. Zone, Proliferation zone. $\boldsymbol{B}$, Representative $z$-projections of control and $\mathrm{T}_{3}$-treated brains stained with Sytox- 0 are shown as montages. Treatment with $\mathrm{T}_{3}$ induced substantial changes in morphology in the telencephalon, pretectum, optic tectum, and hindbrain. Also indicated are the neuropil, cell body layer, and proliferative zone of the optic tectum. $C$, Representative confocal $z$-projections of tecta from the two experimental groups. The fuchsia and blue lines in the control (left) show where measurements of tectal length and width were taken, respectively. $\boldsymbol{D}, \boldsymbol{E}, \mathrm{T}_{3}$ induced an increase in the volume $(\boldsymbol{D})$ and width/length ratio $(\boldsymbol{E})$ of the tectum $\left({ }^{* *} p<0.01,{ }^{* * *} p<0.001\right)$. $\boldsymbol{F}$, Volume and width/length ratio significantly covaried $\left(r^{2}=0.57, p<0.01\right)$.

liferation, neuronal differentiation, and morphological changes underlying brain development. Although a surge of circulating TH drives metamorphosis in mature tadpoles (2-6 months after fertilization, depending on husbandry conditions; Nieuwkoop and Faber, 1956; Kelley, 1996), younger tadpoles are acutely sensitive to TH (Gudernatsch, 1912; Tata, 1968; Shi, 2000).

Thyroxine $\left(\mathrm{T}_{4}\right)$ is produced in the thyroid gland and circulates throughout the body. $\mathrm{T}_{4}$ is converted locally in the brain to triiodothyronine $\left(\mathrm{T}_{3}\right)$, the active form of TH, by type-II 5-deiodinase. Similarly, local expression of type-III 5-deiodinase (DIO3) converts $\mathrm{T}_{3}$ to an inactive form. During brain development, $\mathrm{T}_{3}$ predominantly binds thyroid hormone receptor $\alpha$ (TR $\alpha)$, a transcription factor that represses gene expression when unliganded (Oppenheimer and Schwartz, 1997; Havis et al., 2006; Bernal, 2007; Choi et al., 2015; Wen and Shi, 2015). This combination of circulating levels of $\mathrm{T}_{4}$ and expression of deiodinases and TRs governs spatial and temporal TH signaling in the brain. Nevertheless, most studies on $\mathrm{TH}$ in brain development manipulate circulating levels of TH without addressing how local TH signaling affects specific components of a developing TH-sensitive neural circuit. We investigated potential local effects of TH signaling on development of the Xenopus laevis tadpole optic tectum, the homolog of the mammalian superior colliculus, when tadpoles are about 1 week old and begin to forage for food. Neural progenitor cell (NPC) proliferation, neuronal differentiation, and retinotectal circuit assembly have been well characterized during this developmental period (Bestman et al., 2008, 2012, 2015). We used spatial and temporal manipulations of TH signaling, including global and local delivery of $\mathrm{T}_{3}$, targeted DIO3 knockdown in the tectum, and drug treatments, combined with analysis of brain morphology, neurogenesis, cell death, neuronal differentiation, and gene expression. We also used time-lapse in vivo imaging to examine distinct responses of neural progenitor cells and neurons to $\mathrm{T}_{3}$ over time. Our data show that localized increases in $\mathrm{TH}$ signaling induce rapid and robust increases in cell proliferation, neuronal differentiation, and dendrite arbor development and that blocking endogenous $\mathrm{TH}$ synthesis reduces proliferation in the optic tectum. We conclude that $\mathrm{TH}$ at these developmental stages drives neurogenic events essential for neural circuit assembly.

\section{Materials and Methods}

Animals. We used albino X. laevis tadpoles that were bred on site. Tadpoles of either sex were reared in $0.1 \times$ Steinberg's solution (12 h light/ dark cycle at $22^{\circ} \mathrm{C}$ ). Tadpoles were selected for study based on their developmental stage using the morphological criteria of Nieuwkoop and Faber (1956) at the beginning of each experiment. Xenopus tadpoles are free-swimming 3-4 d after fertilization [stages 38-41, as defined by Nieuwkoop and Faber (1956))]. By 5-7 d, tadpoles have exhausted their yolk stores and begin to forage for food. We use tadpoles during these stages (stages 46-49) while the retinotectal circuit continues to undergo substantial development (Tao and Poo, 2005; Bestman et al., 2008, 2012, 2015; Deeg et al., 2009; Pratt and Aizenman, 2009; Shen et al., 2011, 2014). Under standard rearing conditions in our laboratory, stage 46 lasts $1 \mathrm{~d}$, stage 47 continues for 2-3 d, stage 48 lasts 5 or more days, and stage 49 typically lasts an additional 5-6 d. Thus stage 46 tadpoles will typically progress to stage 48 after 1 week and to stage 49 over 2 weeks. During hormone bath experiments, we kept the tadpoles in bowls with $100 \mathrm{ml}$ of $0.1 \times$ Steinberg's solution (see below for details about hormone experiments). Tadpoles were fed tadpole powder (Xenopus Express) twice a day, and waste was removed as needed. During in vivo imaging experiments, tadpoles were housed individually in wells of six-well tissue culture plates. We anesthetized tadpoles in $0.02 \%$ MS222 before electroporation, coconut oil injection, and during in vivo imaging. All animal procedures were performed in accordance with The Scripps Research Institute's institutional animal care and use committee's regula- 
Table 1. Primers used for quantification of gene expression

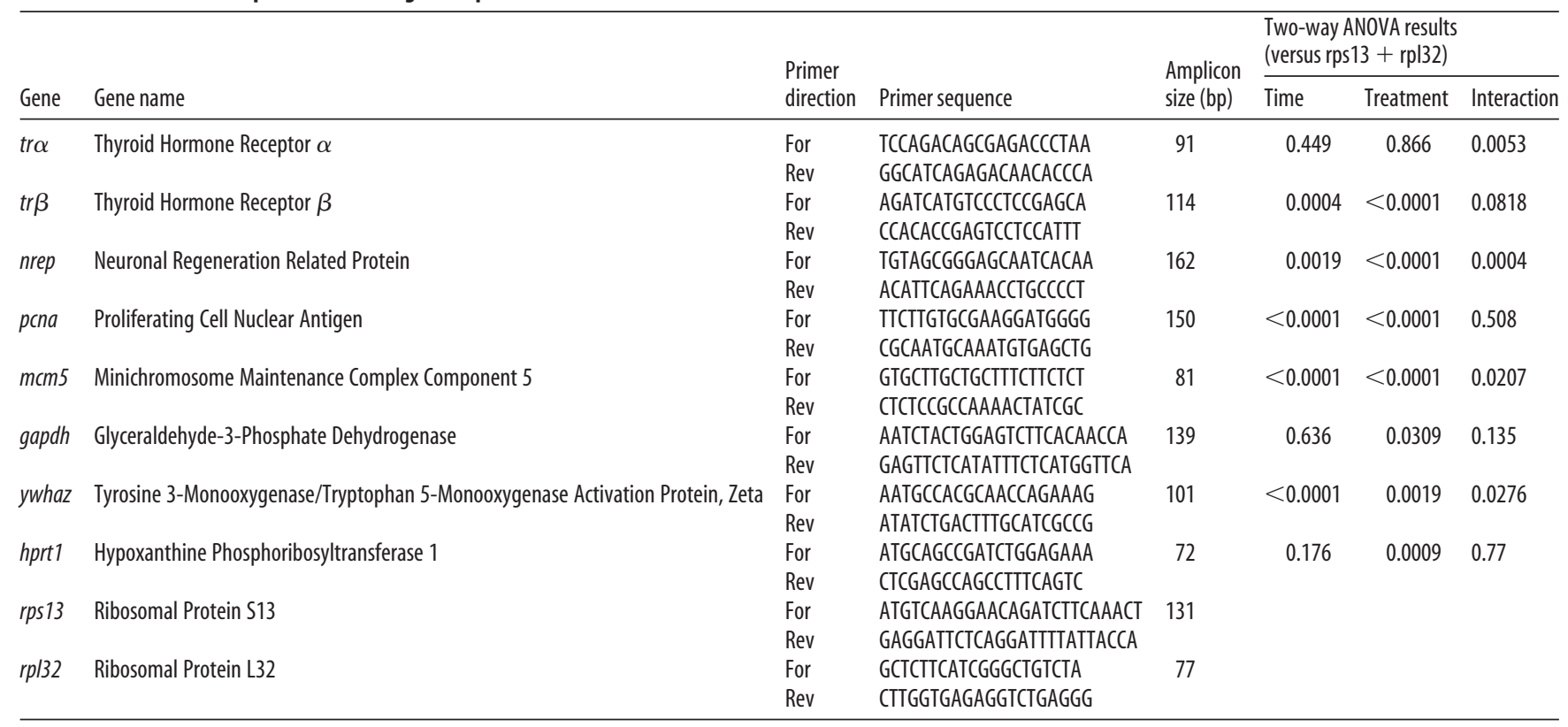

Forward and reverse primer sequences that were used for quantification of expression for specified genes are shown. Analysis using two-way ANOVA compared with the ribosomal proteins, rps 13 and rpl132, is shown.

Table 2. Candidates evaluated for use as reference genes

\begin{tabular}{|c|c|c|c|c|c|c|c|}
\hline \multirow[b]{2}{*}{ Gene } & \multicolumn{2}{|c|}{$\begin{array}{l}\text { Percent difference } \\
\text { of T3 from Control }\end{array}$} & \multicolumn{3}{|c|}{ Two-way ANOVA results } & \multirow{2}{*}{$\begin{array}{l}\text { geNorm } \\
\text { M-value }\end{array}$} & \multirow{2}{*}{$\begin{array}{l}\text { NormFinder } \\
\text { Stability value }\end{array}$} \\
\hline & Day 2 & Day 4 & Time & Treatment & Interaction & & \\
\hline gapdh & 16.4 & 60.0 & 0.576 & 0.025 & 0.266 & 0.607 & 0.0186 \\
\hline ywhaz & 67.6 & 49.2 & $<0.001$ & $<0.001$ & 0.125 & 0.568 & 0.0711 \\
\hline hprt1 & 54.9 & 109.9 & 0.542 & $<0.001$ & 0.421 & 0.563 & 0.0454 \\
\hline rps13 & 1.9 & 19.8 & 0.012 & 0.516 & 0.627 & 0.710 & 0.0819 \\
\hline$r p / 32$ & 13.9 & 30.0 & 0.008 & 0.111 & 0.43 & 0.736 & 0.0692 \\
\hline
\end{tabular}

Candidates were evaluated to determine if the genes respond to $\mathrm{T}_{3}$ treatment and for their stability as potential reference genes using geNorm and NormFinder analysis tools.

tions. The number of animals used in each experiment is listed in the figure legends.

Hormone and drug treatments. For systemic treatment experiments in which $\mathrm{T}_{3}$ was delivered in rearing solution, $\mathrm{T}_{3}(20 \mu \mathrm{g} / \mathrm{ml}$; Sigma) was dissolved in $20 \mathrm{~mm} \mathrm{NaOH}$ stock solution and stored at $-20^{\circ} \mathrm{C}$. Aliquots of $\mathrm{T}_{3}$ stock were thawed and diluted to $50 \mathrm{~nm}$ in Steinberg's solution, a concentration that is effective in activating TH signaling in the tadpole brain (Denver et al., 2009). Methimazole (MMI; $0.114 \mathrm{~g} / \mathrm{ml}$ ) was dissolved in double-distilled $\mathrm{H}_{2} \mathrm{O}$ and stored at $-20^{\circ} \mathrm{C}$. Aliquots of MMI stock were thawed and diluted to $1 \mathrm{~mm}$ in Steinberg's solution. Except where stated otherwise, tadpoles used in hormone treatment experiments were kept in bowls with $100 \mathrm{ml}$ of Steinberg's solution (20-30 tadpoles per bowl). To deliver $\mathrm{T}_{3}$ locally to the eye and midbrain, we prepared suspensions of crystalline $\mathrm{T}_{3}$ in melted $\left(35^{\circ} \mathrm{C}\right)$ coconut oil $(20$ $\mathrm{mg} / \mathrm{ml}$ ), vortexed the mixture for $\sim 5 \mathrm{~min}$, and diluted it to four concentrations $(5 \mathrm{mg} / \mathrm{ml}, 1 \mathrm{mg} / \mathrm{ml}, 500 \mu \mathrm{g} / \mathrm{ml}, 100 \mu \mathrm{g} / \mathrm{ml})$ in coconut oil.

Chloro-deoxyuridine incorporation to label dividing cells. Chlorodeoxyuridine (CldU; $10 \mathrm{mg} / \mathrm{ml}$; 105478, MP Biomedicals) was dissolved in distilled $\mathrm{H}_{2} \mathrm{O}$ to generate $38.1 \mathrm{~mm}$ stock, which was then diluted to 10 $\mathrm{mm}$ in Steinberg's solution. We placed tadpoles in $10 \mathrm{~mm}$ CldU solution for $2 \mathrm{~h}$ and then either killed them immediately (see below) or returned them to their treatment bowl for pulse/chase analysis.

Euthanasia and tissue fixation. Tadpoles were killed with an overdose of anesthesia (1.0\% MS222) and fixed in 4\% phosphate-buffered paraformaldehyde overnight at $4^{\circ} \mathrm{C}$. We then washed the tadpoles with PBS and dissected the brains into PBS with $0.1 \%$ Triton X-100 (PBS-TX). Tadpoles that were used for coconut oil experiments in the eye and the brain were fixed with $2 \%$ trichloro-acetic acid for $2 \mathrm{~h}$ and placed into PBS before being embedded in paraffin.
Whole-mount immunostaining and imaging. Tadpole brains were washed in PBS-TX, placed in blocking buffer (2.5\% normal goat serum in PBS-TX) for $1 \mathrm{~h}$, and incubated overnight in the primary antibody [phosphoHistone3 (pH3), 1:1000, Sigma-Aldrich, H0412, made in rabbit, RRID: AB_477043; BrdU, 1:200, Accurate, made in rat, RRID: AB_609568; HuC/D, 1:200, Invitrogen, A21271, made in mouse, RRID: AB_221448; GFP, 1:200, Millipore, ab3080, made in rabbit, RRID: AB_91337] in blocking buffer at $4^{\circ} \mathrm{C}$ with gentle rotation. We then washed the brains three times in PBS-TX, incubated them in the appropriate secondary antibody [pH3, BrdU, GFP with Alexa Fluor 488 (1:400), HuC/D with Alexa Fluor 633 (1:400); Life Technologies] for 3-4h, washed them again in PBS-TX, and incubated them for $15 \mathrm{~min}$ in Sytox-O (1:1000 in PBS-TX). Brains were washed in PBS once and coverslipped in a well on a slide with Prolong Gold antifade mounting medium (Life Technologies). Immunostained brains were imaged on a FluoView 500 confocal microscope or a Nikon multiphoton microscope.

Quantification of animal length and brain morphology. We measured the body lengths of fixed tadpoles from snout to tail tip in ImageJ from images taken with an Infinityl camera mounted on a Nikon dissecting microscope. We measured the volume of the tectum by tracing the crosssectional area of the tectum every five optical sections $(6.2 \mu \mathrm{m})$ with a Wacom graphic tablet using ImageJ (RRID: SCR_003070). Tectum volume was calculated using the formula for the volume of a cone frustum using the cross-sectional areas from every other five optical sections as the top and bottom of the frustum and adding the volume segments to obtain total tectum volume. To measure the tectum width/length ratio, we measured the width of the tectum (defined as a line connecting the most lateral extent of where the cell body layer meets the neuropil on either side of the brain) and the length of the tectum (defined as a line connecting the anterior tectal commissure to the point at which the midline of the ventricular zone starts to extend laterally). The width/ length ratios were measured from a $z$-projection of the same confocal stacks used to measure tectal volume. We used the width/length ratio as a measure of change in tectum morphology because it appeared to be a more sensitive measure of the effects of $\mathrm{T}_{3}$ than total volume (Fig. $1 F-H$ ). The width/length ratio has previously been shown to be a sensitive indicator of metamorphic change in the tadpole brain (Coen et al., 2007).

Quantification of cell number. We counted the number of CldU+, $\mathrm{pH} 3+$, and dying Sytox-O + cells from optical stacks of whole imaged tecta in ImageJ. The area of the tectum that was quantified was delineated by the anterior commissure on the rostral side, the most caudal extent of the midbrain ventricle, the dorsal surface of the brain, and the top 40 or 55 optical sections of tectum were used to delineate the 
A

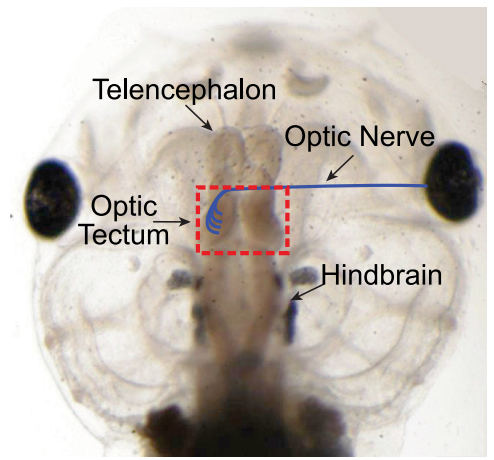

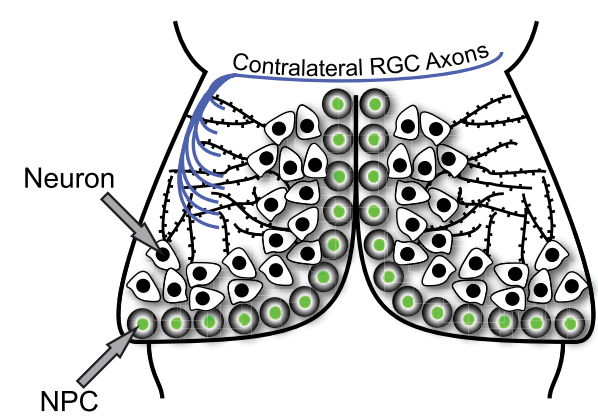

NPC

B

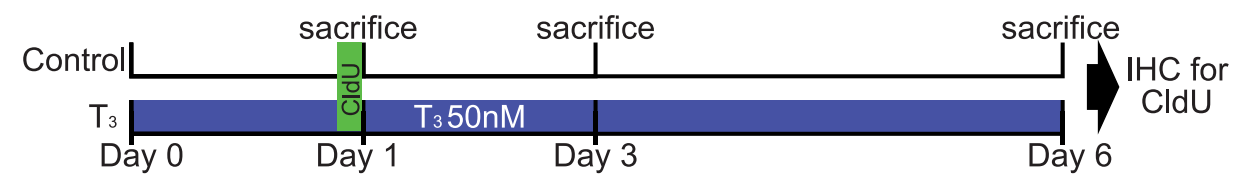

C

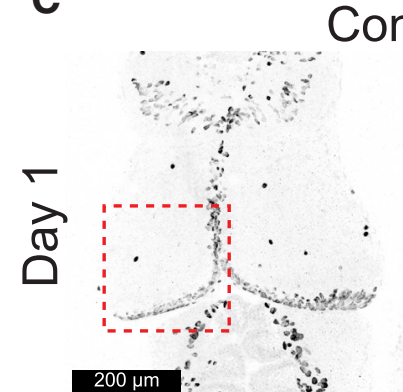

Control

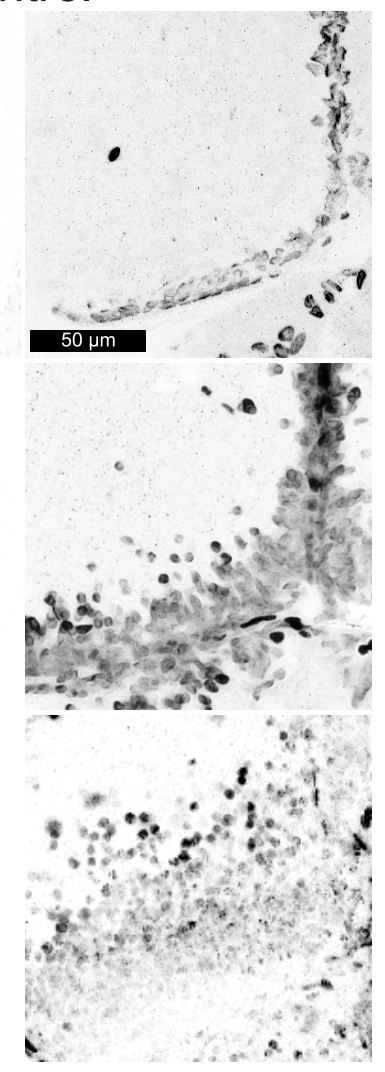

$T_{3}$

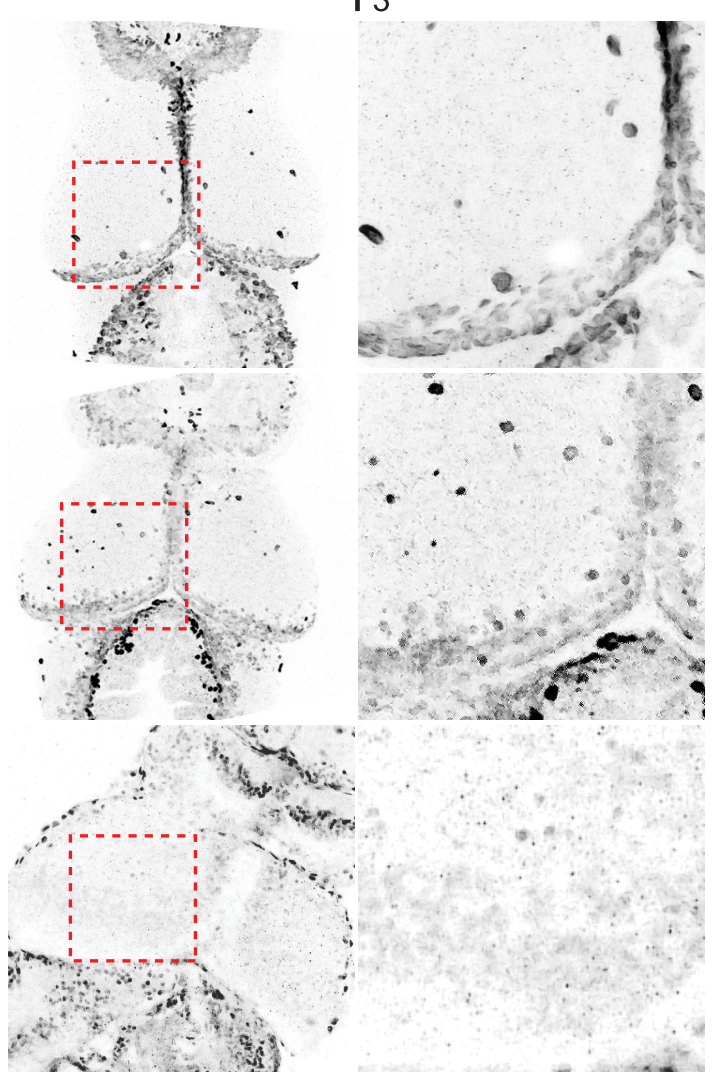

Figure 2. $T_{3}$ treatment increases NPC proliferation in the optic tectum. $A$, Dorsal aspect of a Xenopus tadpole head illustrating the major subdivisions of the brain and retinal innervation of the optic tectum. $\boldsymbol{B}$, Schematic of area highlighted in red box in $\boldsymbol{A}$ illustrating the cellular makeup of the tadpole retinotectal circuit. The contralateral retinal ganglion cell axons (blue) synapse on dendrites of tectal neurons (black nuclei) in the neuropil. NPCs (green nuclei) situated along the ventricle generate neurons that make up the cell body layers. C, Protocol for $\mathrm{T}_{3}$ and CldU treatments, followed by immunohistochemical (IHC) labeling for CldU. Stage 47 tadpoles were placed in either control bath or $\mathrm{T}_{3}$ bath $(50 \mathrm{~nm})$. Tadpoles were exposed to CldU for $2 \mathrm{~h}$ at the end of the first $24 \mathrm{~h}$. Groups of tadpoles were killed on day 1 (immediately after $2 \mathrm{~h}$ (IdU exposure), day 3, or day 6. C, Confocal $\mathrm{z}$-projections of representative tecta from tadpoles in each group killed at the designated time point. A high-magnification view of each tectum within the dashed box is shown to the right. Black and white images were inverted so CldU labeling is black. Quantification showed that $1 \mathrm{~d}$ treatment with $\mathrm{T}_{3}$ significantly increased tectal NPC proliferation (see Results). CldU labeling in the $\mathrm{T}_{3}$ group progressively decreased over days 3 and 6 , consistent with dilution of CldU. $n=6-8$ brains per group.

ventral extent of the region of interest. For CldU and $\mathrm{pH} 3$, we counted cells that met a threshold fluorescence intensity of at least three times the intensity of background. We counted brightly labeled Sytox-O+ cells, a measure of apoptotic cells, as described by Faulkner et al. (2015), that met a threshold intensity of at least 1.5 times the intensity of their nearest neighboring cells. Dying Sytox-O+ cells were also characterized as having a relatively small, condensed nucleus. A sig- nificant portion of these cells also colocalize with activated capase- 3 (Faulkner et al., 2015).

For analysis of CldU labeling in paraffin sections, we killed tadpoles, fixed them with $2 \%$ trichloro-acetic acid (see above), and embedded the entire tadpole in paraffin using a paraffin embedding system (Thermo Fisher Scientific). We cut the heads using a rotary microtome into $5-\mu \mathrm{m}$ thick slices and mounted the sections onto Superfrost slides (Thermo 

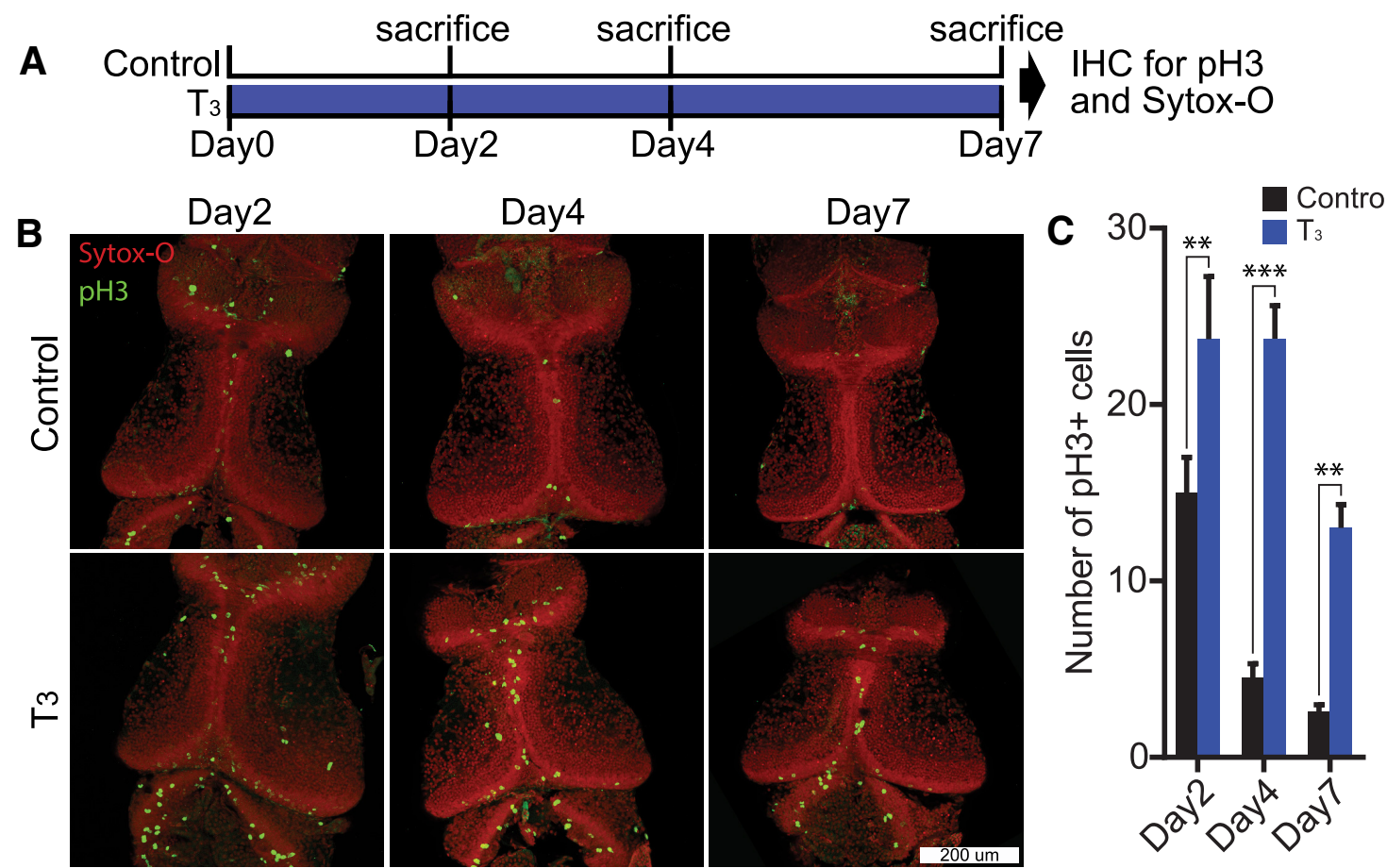

Figure 3. $\mathrm{T}_{3}$ increases tectal NPC proliferation. $A$, Protocol for $\mathrm{T}_{3}$ treatments, followed by immunohistochemical (IHC) labeling for pH3. Stage 47 tadpoles were put into either control bath or $\mathrm{T}_{3}$ bath $(50 \mathrm{~nm})$ for $7 \mathrm{~d}$. Tadpoles from both groups were killed 2, 4, and $7 \mathrm{~d}$ after onset of treatment. $\boldsymbol{B}$, Representative confocal $z$-projections of optic tecta immunolabeled for pH3 (green) and counterstained with Sytox- 0 (red). C, Treatment with $\mathrm{T}_{3}$ significantly increased the number of pH3 + cells in the ventricular zone at all three time points ${ }^{* *} p<0.01$, $\left.{ }^{* * *} p<0.001\right) . n=10-14$ brains per group.

Fisher Scientific) in a warm water bath. We incubated the slides in a $50^{\circ} \mathrm{C}$ incubator overnight, cooled the slides, and deparaffinized them in xylene. Slides were washed in a descending gradient of EtOH, washed in deionized water, and washed in PBS. The sections were dried briefly and outlined with a PAP pen (Sigma), washed further with PBS, incubated with blocking buffer (see above) for $1 \mathrm{~h}$, and incubated with a primary antibody against BrdU (1:200, made in rat; Accurate) overnight. We washed the slides with PBS, incubated the sections with an anti-rat biotinylated secondary antibody for $90 \mathrm{~min}$, washed with PBS, incubated with the ABC kit (Vector Laboratories) for $45 \mathrm{~min}$, washed with PBS, and revealed immunolabel with a diaminobenzidine-based colorimetric reaction. We washed the sections with PBS and water, stained them with a hematoxolin solution for $1 \mathrm{~min}$, washed with water, dehydrated in an ascending series of EtOH, cleared in xylene, and coverslipped with DPX. We counted CldU + cells (see Fig. $7 D$, brown precipitate, arrowheads) in every other section in at least 10 sections per eye ( $\sim 5$ sections nasal/ temporal to the punctum caecum). CldU + cells in the retina were found in the ventral and dorsal ciliary margin. We counted CldU + cells in every other section in at least 10 sections in the midbrain, starting from the caudal end of the midbrain and moving rostrally. We counted all CldU+ cells that lined the midbrain ventricle; this includes cells from the tectum and tegmentum.

Electroporation, morpholinos, plasmids, and in vivo imaging. Optic tecta were electroporated with plasmids or morpholinos as described previously (Bestman and Cline, 2014; Bestman et al., 2015). Morpholinos against the 5'UTR region of DIO3 (DIO3 MO: GCAGTGCAACATGGTGCTCAGCCCT) or control morpholinos (control MO: TAACTCGCATCGTAGATTGACTAAA) were designed by GeneTools. For in vivo imaging of NPC proliferation and neuronal differentiation, we electroporated optic tecta of stage 46 tadpoles with a construct, called pSox2-bd::GFP, that drives GFP expression in Sox2-expressing NPCs (Bestman et al., 2012). We counted the GFP+ cells that had morphological features of either neurons (pear-shaped cell body, dendritic arbor, and a fine axonal process, often tipped with a growth cone) or NPCs (columnar-shaped cell body in or adjacent to the ventricular zone extending a process with end feet adjacent to the pia). These criteria for identification of NPCs and neurons have been described previ- ously (Bestman et al., 2012). Cells that had ambiguous features were designated as unclassifiable. We quantified the change in the number of GFP+ neurons or NPCs and the total number of GFP + cells over the $3 \mathrm{~d}$ of imaging, relative to the numbers on first day of imaging.

To test for efficacy of morpholino-mediated knockdown of DIO3, we electroporated optic tecta of stage 46 tadpoles with control morpholinos or morpholinos against DIO3 along with two plasmids: pSox2bd::Gal4/ UAS::DIO3-t2A-eGFP and UAS::tRFP ${ }_{\text {nls }}$. All tRFP+ cells had also been transfected with the DIO3-t2A-eGFP plasmid, since the tRFP can only be expressed in the presence of Gal4. DIO3 MO-mediated knockdown of DIO3 would also decrease GFP expression in RFP+ cells, as described by Faulkner et al. (2015). After 2-3 d, we imaged GFP and RFP in tecta using a PerkinElmer spinning-disk confocal microscope. We established image acquisition conditions in tecta electroporated with control MO to ensure that eGFP fluorescence in individual cells was not saturated. We used tRFP expression at the largest cross-sectional area in the nucleus as the search criterion and measured the eGFP intensity in the green channel. We also calculated the percentage of tRFP + cells that were also eGFP+. Cells were considered to be eGFP + if intensity of GFP fluorescence was more than three times the background intensity, taken from areas free of visible label. There was some bleedthrough of tRFP into the green channel, but the level of fluorescence was almost always less than three times the background. The eGFP fluorescence intensity was analyzed in ImageJ. We analyzed at least 10 cells per tadpole (control MO, $n=19$; DIO3 MO, $n=13$ ).

To label optic tectal neurons for in vivo time-lapse imaging of dendritic arbor structure, we sparsely electroporated optic tecta of stage 46 tadpoles with a GFP-expressing plasmid ( $\mathrm{p} \alpha$-actinin::GAL4/UAS::eGFP) and imaged fields containing one to three neurons with a two-photon microscope starting $6 \mathrm{~d}$ later. Immediately after collecting the first image, we injected either $\mathrm{T}_{3}$-free melted coconut oil (ControlCO) or $\mathrm{T}_{3}$ in coconut oil $\left(\mathrm{T}_{3} \mathrm{CO}\right)$ and imaged the same cells each day over the following $3 \mathrm{~d}$. 3D renderings of the entire dendritic arbor structures were generated in Imaris (RRID:SCR_007370), and the entire extent of the dendritic arbor of each neuron was reconstructed across all three time points. We 
A
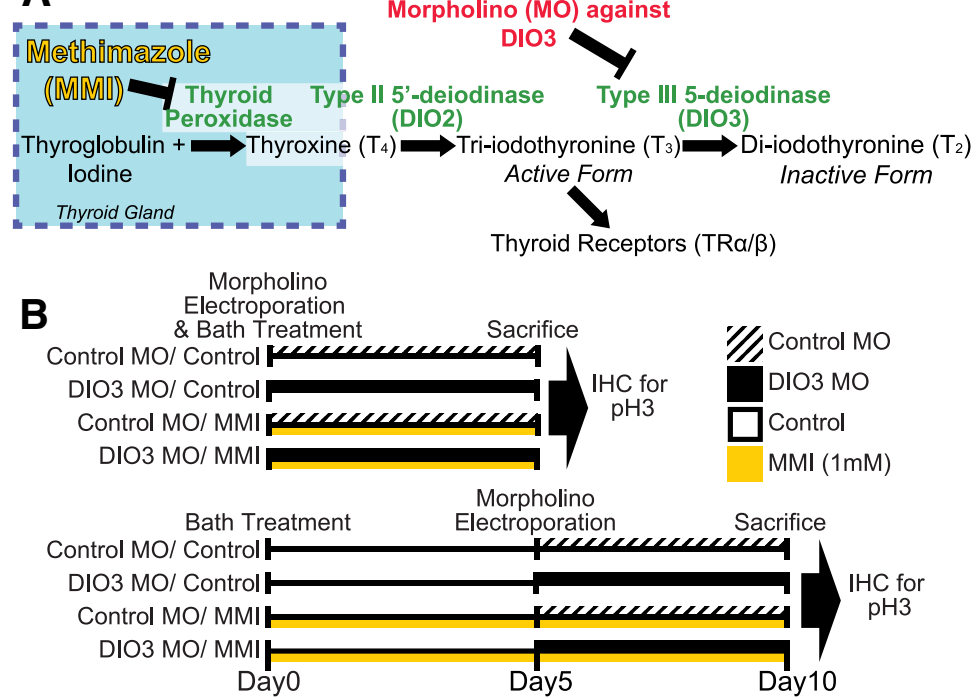

C
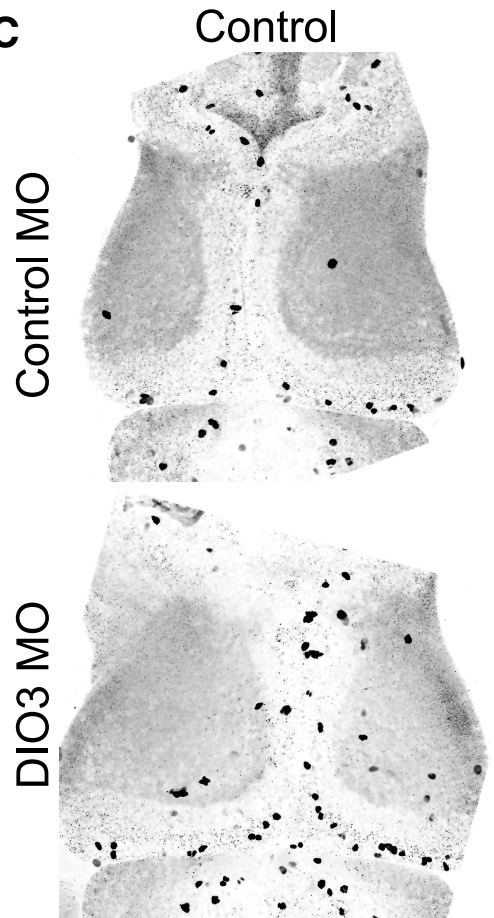

D

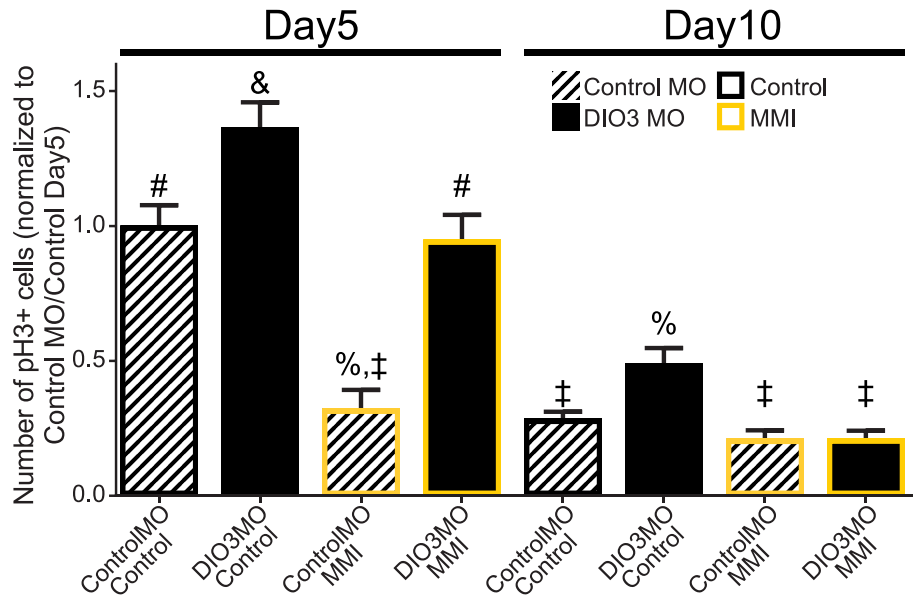

Figure 4. Local control of endogenous TH metabolism regulates tectal NPC proliferation. $\boldsymbol{A}$, Schematic of TH synthesis and control of local TH action and availability. MMI blocks TH synthesis, and DI03 expression increases the local availability of $\mathrm{T}_{3} . \boldsymbol{B}$, Timeline of experiment. Tadpoles were placed in control bath or bath containing MMI. Half the tadpoles in each treatment group

quantified dendritic branch tip number and total dendritic arbor branch length.

Quantification of gene expression. We performed two experiments that quantified changes in gene expression. First, two groups of 10 stage 46 tadpoles were electroporated with either DIO3 MO or control MO and killed 5 d later by overdose of MS222 (1\%). Second, 32 stage 46 tadpoles were split into two groups and placed into either Steinberg's solution (control) or Steinberg's solution with $50 \mathrm{nM} \mathrm{T}_{3}$. Tadpoles were killed either 2 or $4 \mathrm{~d}$ later by overdose of MS222. We quickly dissected the brains rostral to the hindbrain-spinal cord junction, placed them into Trizol (Life Technologies), and froze them in $-80^{\circ} \mathrm{C}$. We extracted RNA per the manufacturer's instructions for Trizol, measured the amount of RNA extracted on a NanoDrop, and reverse transcribed the mRNA using the iScript kit (BioRad), using 200 ng of RNA per reaction. We performed quantitative PCR (qPCR) using 2 ng of cDNA per reaction using the iTaq Universal SYBR Green Supermix kit (Bio-Rad) on a Bio-Rad CFX96 thermocylcer. A description of primers used is in Table 1. All reactions were done with technical triplicates; outlier reactions (deviations more than 1.5 times the SD from the mean) within a set of triplicates were removed from analysis. We used a two-step reaction with a $10 \mathrm{~s} 95^{\circ}$ melt step, followed by a $30 \mathrm{~s} 60^{\circ}$ annealing and an extension step for 40 cycles, with fluorescence measured at the end of every $60^{\circ}$ step. At the end of 40 cycles, we evaluated the melt curves for secondary products. None of the primers used in this study generated secondary products.

We evaluated five candidate genes for use as a reference (Table 2) based on the following two criteria: (1) to determine how the genes respond to $\mathrm{T}_{3}$ treatment, we used two-way ANOVA on all data points normalized to the highest data point for each gene across all treatments and time points; and (2) we examined stability of potential reference genes using the geNorm (RRID:SCR_006763) and Norm-

were electroporated with DI03 MO or control M0; the other half were electroporated $5 \mathrm{~d}$ later. Tadpoles were killed $5 \mathrm{~d}$ after electroporation, and brains were labeled for pH3. C, Representative confocal z-projections of tecta showing $\mathrm{pH} 3+\mathrm{la}$ beling. Images were inverted and contrast was increased to reveal nonlabeled features of the brain. $\boldsymbol{D}$, Bar graph of the number of pH3 + cells. In the day 5 treatment group, DI03 MO alone significantly increased cell proliferation in the tectum and MMI treatment alone significantly decreased cell proliferation. The combination of DI03 MO and MMI bath was intermediate between both conditions. In the day 10 ControlM0/ control bath group, cell proliferation was lower than the corresponding day 5 group. DI03 MO alone significantly increased tectal cell proliferation relative to control. Cell proliferation in the MMI alone and DI03M0 plus MMI treatment groups were comparable and not different from control for day 5 and day 10 groups. The $10 \mathrm{~d}$ treatment with MMI was sufficient to counteract the effect of DI03 MO on local availability of $T_{3}$. Symbols above bars indicate significant differences from post hoc analysis. $n=11-18$ brains per group. 

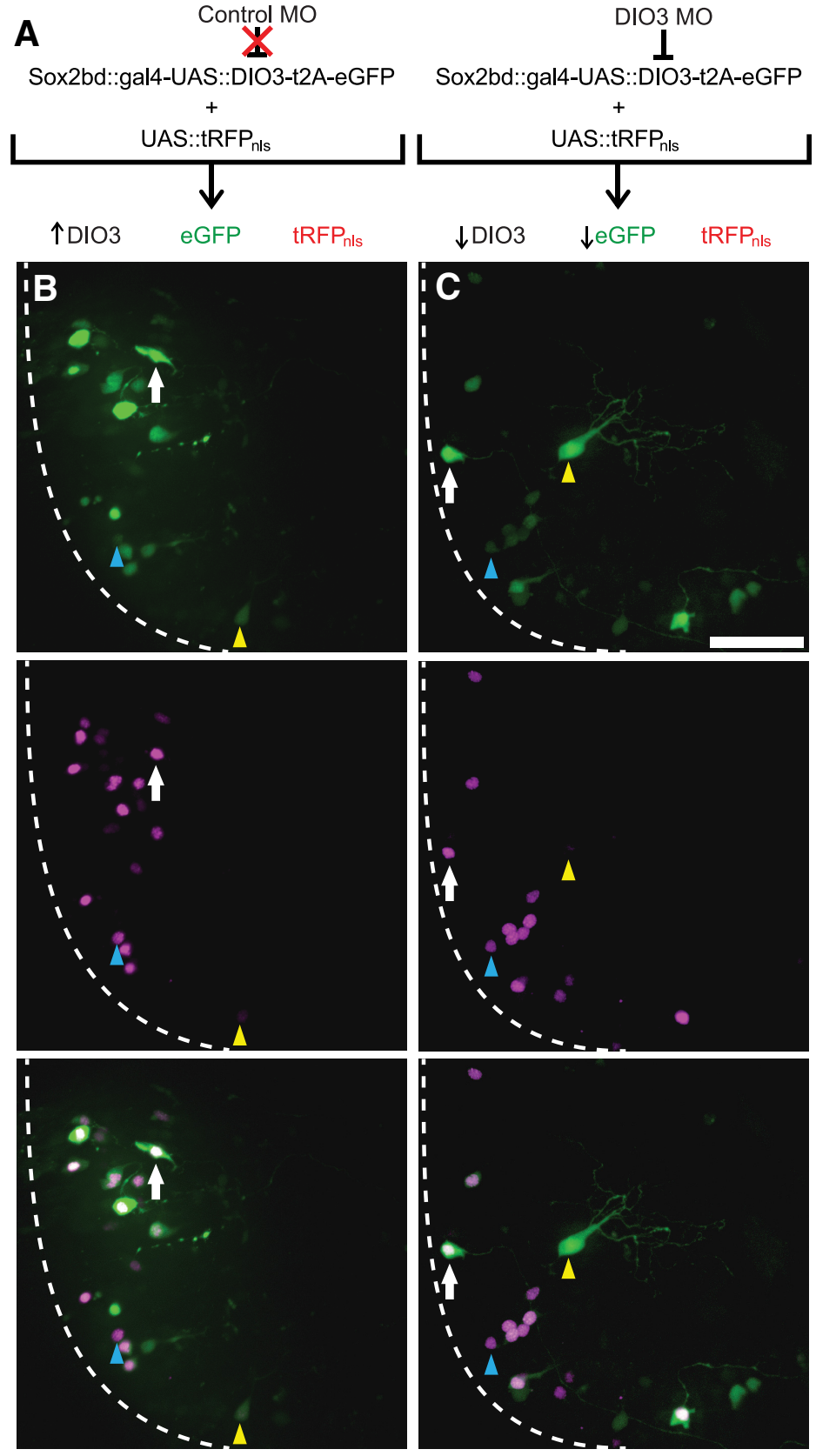

D

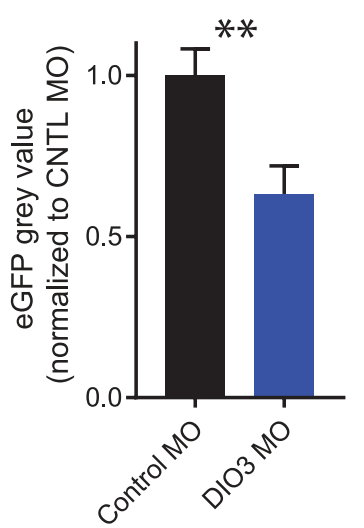

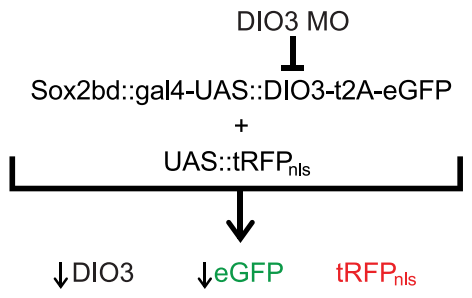
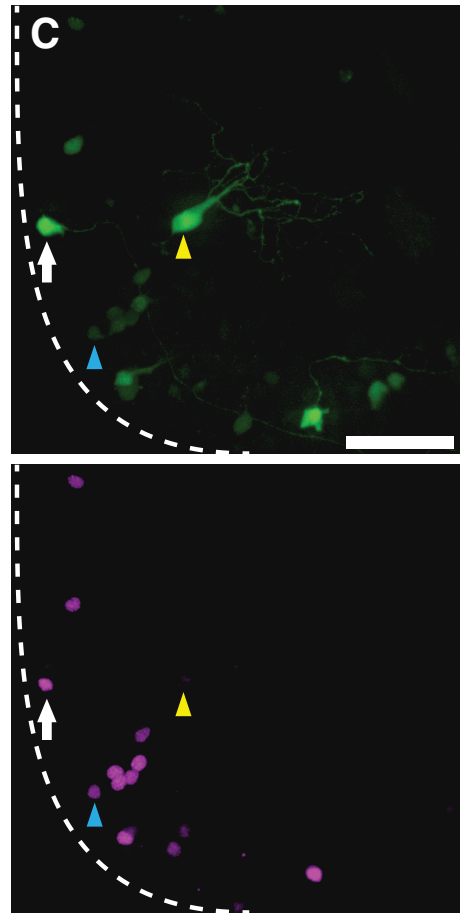

E

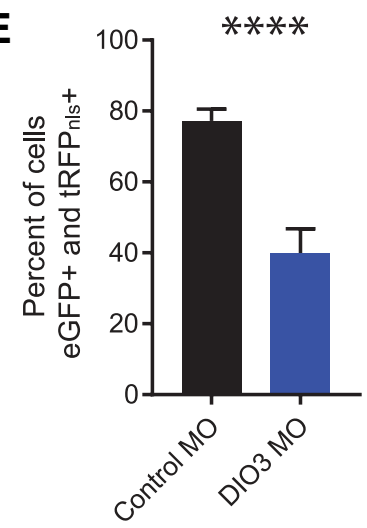

Figure 5. Validation of morpholino-mediated DI03 knockdown. A, Tadpoles were coelectroporated with pSox2bd::gal4-UAS::DI03-t2A-eGFP and UAS::tRFP nls plasmids and either control morpholino (Control M0, left) or morpholino against DI03 (DI03 M0, right). With Control M0, cells express DI03, eGFP, and tRFPnls. DI03 M0 inhibits translation of DI03 and eGFP but does not affect tRFP ${ }_{\text {nls }}$ expression. $\boldsymbol{B}, \boldsymbol{C}$, Example images of right tecta (ventricle indicated by dotted line) treated with

Finder (RRID:SCR_003387) analysis tools in Excel (Microsoft). rps13 and rpl32 met our criteria to be used as reference genes, so we evaluated the expression of target genes using the comparative $\mathrm{Ct}$ method against the mean expression per brain of these genes.

Statistics. We used GraphPad Prism (RRID: SCR_002798) to analyze our data for statistical differences. We used regression analysis to evaluate the relationship of optic tectum volume and width/length ratio. Data with only two groups were evaluated with Student's $t$ test. Data sets with more than two groups were evaluated with ANOVA, and post hoc comparisons were made with Tukey's multiple comparisons test. Data sets with two dimensions (e.g., time vs treatment) were evaluated with two-way ANOVA, and post hoc comparisons were made with either Tukey's multiple comparisons test or Dunnett's test when multiple groups were compared with a control group when appropriate. Data sets with repeated measurements (e.g., changes in dendrite morphology) were evaluated with two-way repeatedmeasures ANOVA and post hoc tests with Sidak's multiple comparison test across treatment groups within the same day. Within-animal differences (e.g., left eye vs right eye coconut oil experiment) were evaluated with paired $t$ tests. We set $\alpha=0.05$ for all tests.

\section{Results}

$\mathrm{T}_{3}$ treatment changes

brain morphology

To determine whether TH treatment affects tadpole brain development, we exposed stage 47 tadpoles to either control solution (Steinberg's rearing solution) or $\mathrm{T}_{3}$ (50 nM in Steinberg's solution), as schematized in Figure $1 A$. We killed all animals after $6 \mathrm{~d}$, stained the brains with Sytox-O to label nuclei, and imaged them on a confocal microscope. Six days of treatment with $\mathrm{T}_{3}$ induced massive changes in brain morphology (Fig. 1B). The most obvious morphological change was a decrease in the rostrocaudal length of the brain, primarily due to substantial rearrangement of the neural structures of the brain. The telencephalon became more compact and less like two distinct lobes. Areas of the dorsal pretectum descended to more ventral areas of the brain. The optic tectum increased in volume, growing wider while the rostrocaudal length decreased (Fig.

either Control MO (B) or DI03 M0 (C), illustrating expression of

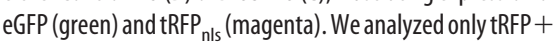
cells, which were either positive for eGFP (white arrows) or negative (below $3 \times$ threshold) for eGFP (blue arrowheads). Cells that expressed only eGFP (yellow arrowheads) were not analyzed. Scale bar, $100 \mu \mathrm{m}$. D, DI03 M0 significantly reduced eGFP intensity in tRFP + cells. $\boldsymbol{E}$, DIO3 MO significantly reduced the percentage of tRFP + cells that were eGFP + . $\left.{ }^{* *} p<0.01,{ }^{* * * *} p<0.0001\right) ; n=13-19$ brains per group. 


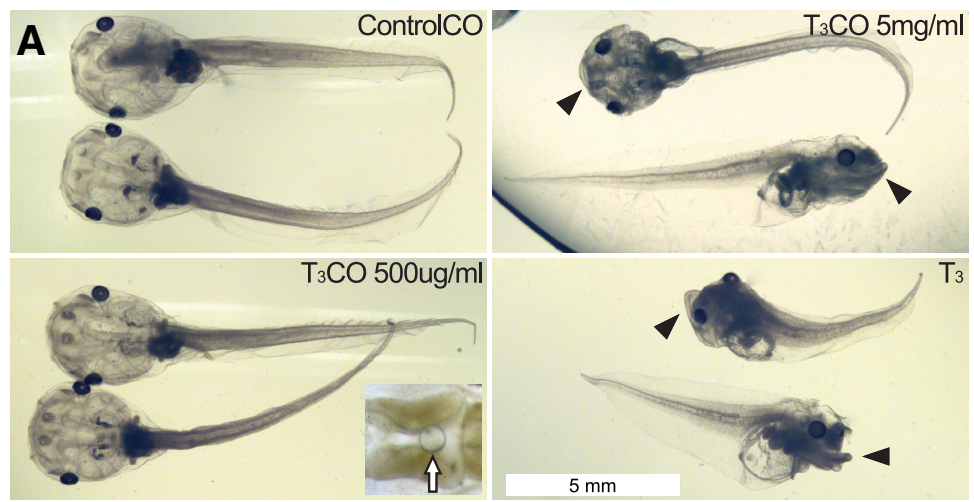

B

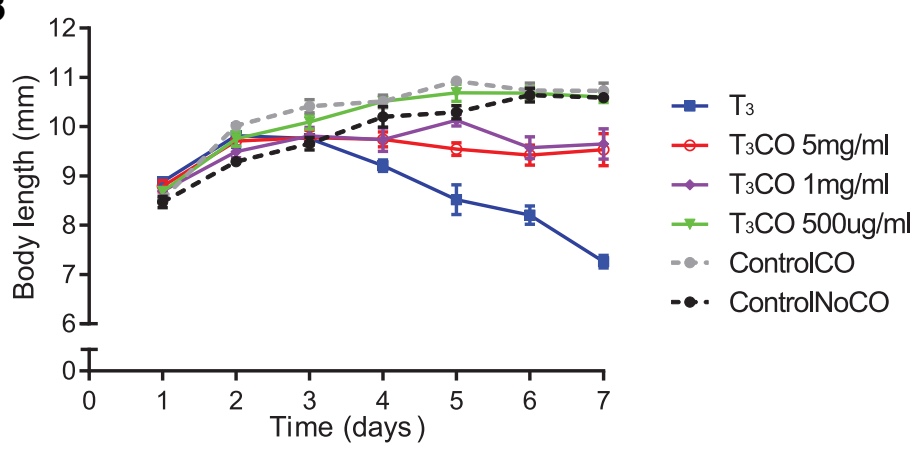

Figure 6. Dose-dependent effect of local delivery of $\mathrm{T}_{3}$ on gross morphology and body length. $A$, Photomicrographs of tadpoles from four designated treatment groups. Tadpoles were treated with $\mathrm{T}_{3}(50 \mathrm{~mm})$ in the bath or injected in the brain ventricle with $\mathrm{T}_{3} \mathrm{CO}$ at three different concentrations. Control animals were reared in control bath or injected with coconut oil without $\mathrm{T}_{3}$ (ControlCO). The inset image at bottom left shows coconut oil droplet (arrow) in the ventricle. $B$, Bath application of $\mathrm{T}_{3}$ affected the whole tadpole, quantified here as a decrease in body length. The two highest concentrations of $\mathrm{T}_{3} \mathrm{CO}$ also significantly decreased body length (2-way ANOVA, effect of treatment, $p<0.001$ ) and changed craniofacial features (see arrowheads in photomicrographs in $A$ ). Tadpoles injected with $500 \mu \mathrm{g} / \mathrm{ml} \mathrm{T}_{3} \mathrm{CO}$ had body length and overall appearance comparable with control groups. $n=8-16$ tadpoles per treatment and time point.

$1 C-F)$, and the dorsoventral height of the midbrain increased by $\sim 40 \%$. Focusing on the optic tectum, we found that $\mathrm{T}_{3}$ induced an increase in the tectal volume (Fig. $1 D ; p<0.01, t$ test) and width/length ratio (Fig. $1 E ; p<0.001$ ). We also found that the tectal volume and width/length ratio significantly covaried (Fig. $1 F ; r^{2}=0.57, p<0.01$ ). These results show that continuous $6 \mathrm{~d}$ treatment with $\mathrm{T}_{3}$ alters tectal morphology, leading to an increase in tectal volume, and that the width/length ratio adequately captures that change. These changes suggest that the brain can respond to premature exposure to $\mathrm{T}_{3}$ with metamorphic-like changes in brain morphology (Allen, 1924; Hughes, 1976; Kollros, 1981; Gona et al., 1988; Coen et al., 2007).

\section{$T_{3}$ increases tectal cell proliferation}

The $\mathrm{T}_{3}$-induced increase in optic tectal volume may be attributable to a number of cellular processes, including changes in NPC proliferation and survival. Tectal NPCs are located adjacent to the midbrain ventricle. NPCs give rise to neurons that are subsequently displaced laterally from the ventricle and become the neuronal cell body layers (Gona et al., 1988; Bestman et al., 2012; Fig. 2A). To test the effects of $\mathrm{T}_{3}$ on NPC proliferation and neurogenesis in the optic tectum, we placed tadpoles into either control solution or $\mathrm{T}_{3}$ solution and $24 \mathrm{~h}$ later exposed animals to the thymidine analog CldU for $2 \mathrm{~h}$. Tadpoles were killed right after CldU exposure, or at day 3 or day 6 after the CldU pulse, and processed to visualize CldU, as shown in the schematic of the protocol (Fig. 2B). CldU labeling in control and $\mathrm{T}_{3}$-treated ani- mals killed right after the $2 \mathrm{~h}$ CldU pulse is strong and is confined to NPCs in the optic tectal proliferative zone adjacent to the ventricle (Fig. 2C, Day 1). Tadpoles treated with $\mathrm{T}_{3}$ for $1 \mathrm{~d}$ and killed immediately after CldU treatment have significantly more CldU + cells $(n=13 ; 166.4 \pm$ 8.4, mean + SEM) in the ventricular zone than control tadpoles $(n=15 ; 122.9 \pm$ 8.8; $t$ test, $p=0.00104)$. On day 3 , intensely labeled CldU+ cells are located lateral to the proliferative zone and more weakly labeled cells are located adjacent to the ventricle in control tadpoles. In the day $3 \mathrm{~T}_{3}$-treated tadpoles, intensely labeled CldU + cells are located laterally from the ventricle, and the intensity of CldU + immunolabeling in cells closer to the ventricle is substantially weaker than in control animals. On day 6, in control tadpoles, CldU+ cells are located throughout the cell body layer, with a gradient of increasing labeling intensity extending from the ventricle to the lateral edge of the cell body layer. This pattern is consistent with asymmetric division of NPCs and dilution of the CldU label as NPCs in the ventricle continue to divide (Denver et al., 2009; Sharma and Cline, 2010; Bestman et al., 2012). In tecta of day $6 \mathrm{~T}_{3}$-treated tadpoles, few intensely labeled CldU + cells can be detected at the lateral edge of the cell body layer. CldU + label in cells adjacent to the ventricle was very weak and only detected with enhanced contrast. Quantification was not possible for tadpoles killed on days 3 and 6 , because of the dilution of CldU and decreased immunolabeling intensity. Results from this experiment show that exposure to $\mathrm{T}_{3}$ increases NPC cell proliferation. Continuous treatment with $\mathrm{T}_{3}$ for $6 \mathrm{~d}$ dilutes $\mathrm{CldU}$ label from continued NPC proliferation, as previously reported (Nicholson and Altman, 1972a; Straznicky and Gaze, 1972; Denver et al., 2009).

To test the hypothesis that long-term $\mathrm{T}_{3}$ exposure increases proliferation in the tadpole optic tectum throughout the $T_{3}$ treatment period, we placed stage 47 tadpoles into either control Steinberg's solution or $\mathrm{T}_{3}(50 \mathrm{~nm})$ for $7 \mathrm{~d}$ (Fig. $3 A$ ). Groups of tadpoles from both treatments were killed 2, 4, and $7 \mathrm{~d}$ after onset of treatment, and brains were immunostained for $\mathrm{pH}$, which labels cells in M phase of the cell cycle (Fig. $3 B)$. Long-term treatment with $\mathrm{T}_{3}$ significantly increased the number of $\mathrm{pH} 3+$ cells in the ventricular zone on day $2(p<$ $0.01)$, day $4(p<0.001)$, and day $7(p<0.01$, ANOVA, post hoc Tukey's test), indicating that continuous $\mathrm{T}_{3}$ treatment increases NPC proliferation throughout the exposure period for up to at least $7 \mathrm{~d}$. These data also show that $\mathrm{T}_{3}$ treatment was able to significantly counteract the normal decreased rate of proliferation seen as tadpoles age.

\section{Local control of endogenous TH metabolism regulates tectal cell proliferation}

The previous experiments indicate that exogenous TH increases NPC proliferation in the optic tectum in premetamorphic tad- 

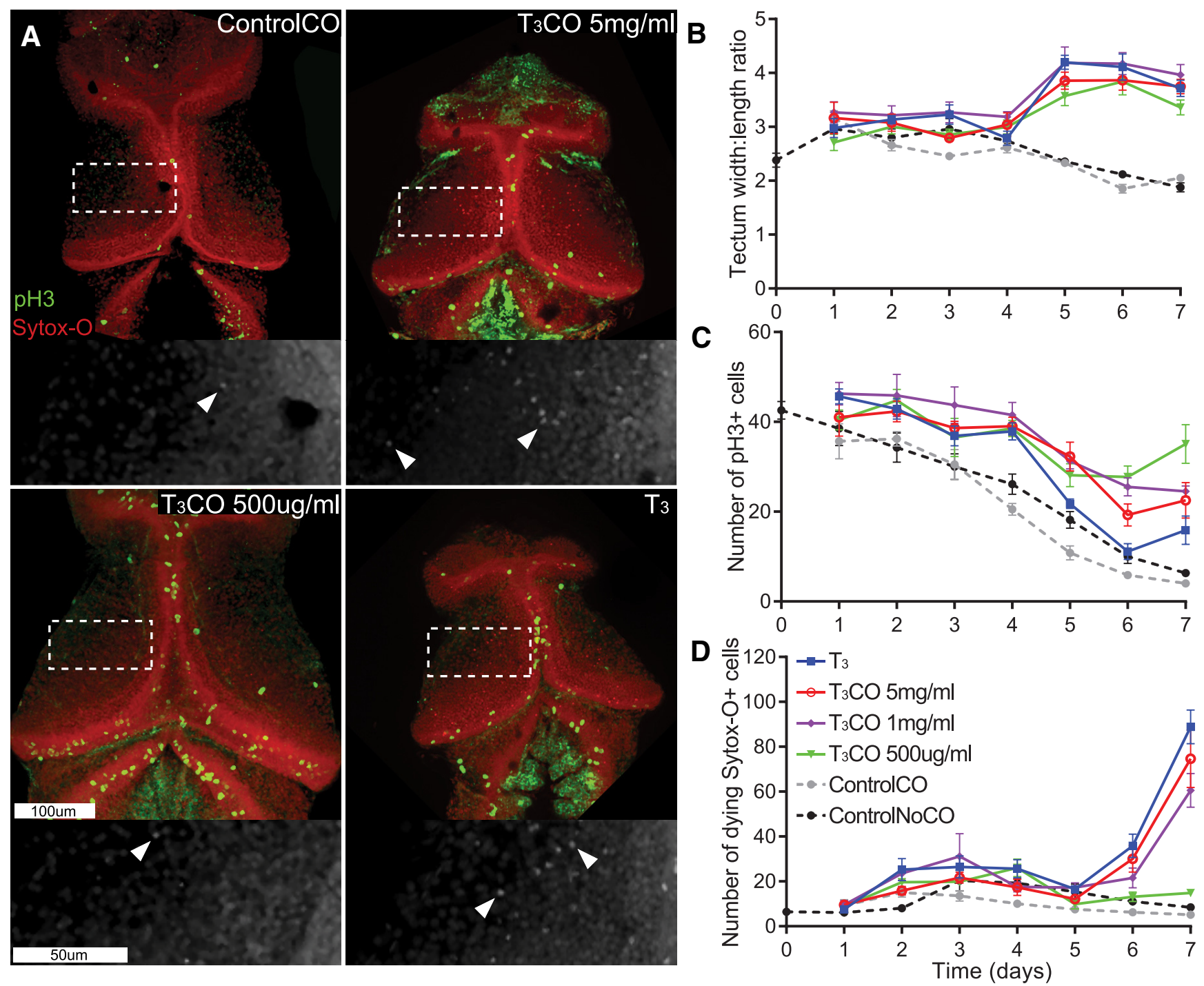

Figure 7. Local delivery of $\mathrm{T}_{3}$ alters tectal morphology and increases NPC proliferation and cell death. $\boldsymbol{A}$, Representative confocal $z$-projections of tecta labeled for $\mathrm{pH} 3$ (green) and Sytox-0 (red) taken at day 7 from four of the treatment groups in this experiment. $\boldsymbol{B}-\boldsymbol{D}$, Plots of quantified neuronal attributes for each day of treatment for six experimental groups. $\boldsymbol{B}$, $\mathrm{T}_{3}$ treatments increased the width/height ratio of optic tecta starting on day 5 relative to control groups (2-way ANOVA, effect of treatment, $p<0.001$ ). $C, T_{3}$ increased the number of $\mathrm{pH} 3+$ cells in the tadpole tecta relative to control groups (2-way ANOVA, effect of treatment, $p<0.001)$. $\boldsymbol{D}$, Bath application of $\mathrm{T}_{3}$ and the highest doses of $\mathrm{T}_{3} \mathrm{CO}$ significantly increased the number of dying Sytox- $0+$ cells on days 6 and 7 (2-way ANOVA, effect of treatment, $p<0.001$ ). The number of dying Sytox- $0+$ cells in the $500 \mu \mathrm{g} / \mathrm{ml} \mathrm{T}_{3} \mathrm{CO} \mathrm{group} \mathrm{did} \mathrm{not} \mathrm{differ}$ from control groups. $n=7-11$ brains per treatment and time point.

pole stages; however, whether endogenous TH affects proliferation in the CNS at these developmental stages is unknown. To address this issue, we manipulated components of the TH signaling pathway shown in Figure 4A. Animals were treated as schematized in Figure $4 B$. We placed tadpoles into control Steinberg's solution or Steinberg's solution containing the goitrogen MMI ( 1 $\mathrm{mM}$ ), which blocks the synthesis of $\mathrm{T}_{4}$ in the thyroid gland (Fig. $4 A$ ). The optic tecta of half the tadpoles were also electroporated with either DIO3 MO or control MO. Tecta of the other half of the tadpoles were electroporated with DIO3 MO or control MO 5 d later (Fig. 4B). Targeted knockdown of DIO3 in the optic tectum is expected to decrease metabolism of active $\mathrm{T} 3$ to inactive $\mathrm{T} 2$ and thereby increase local $\mathrm{T}_{3}$ signaling (Fig. $4 A$ ). Tadpoles were killed $5 \mathrm{~d}$ after electroporation, and brains were either labeled with $\mathrm{pH} 3$ antibodies or processed for qPCR to test for changes in expression of neural regeneration related protein (nrep), a transcript that is known to increase in response to elevated TH signaling (Das et al., 2006). Figure $4 C$ shows represen- tative images of tecta from animals treated for $5 \mathrm{~d}$ with MMI and DIO3 MO. We found that in the day 5 group, DIO3 knockdown without MMI significantly increased the number of $\mathrm{pH} 3+$ cells in the tectum (Fig. 4D, ANOVA and Tukey's post hoc test). Treatment with MMI alone significantly decreased the number of pH3 + cells, and the combination of DIO3 knockdown and MMI treatment was intermediate between both DIO3 knockdown alone and MMI alone. These results suggest that DIO3 MO increases local TH signaling and that MMI decreases circulating TH levels. The intermediate response to both DIO3 MO and MMI suggests that 5 days of MMI treatment is not sufficient to deplete residual $\mathrm{T} 4$ in the brain so that DIO3 knockdown in the tectum can still increase local T3 signaling. In the day 10 group, in which half of the animals were pretreated with MMI before DIO3 MO electroporation (Fig. $4 B$, bottom), the overall level of proliferation was lower than the day 5 group, consistent with the normal decrease in proliferation over this interval (Fig. $3 C$ ). Tadpoles with DIO3 knockdown alone had more pH3 + cells compared 

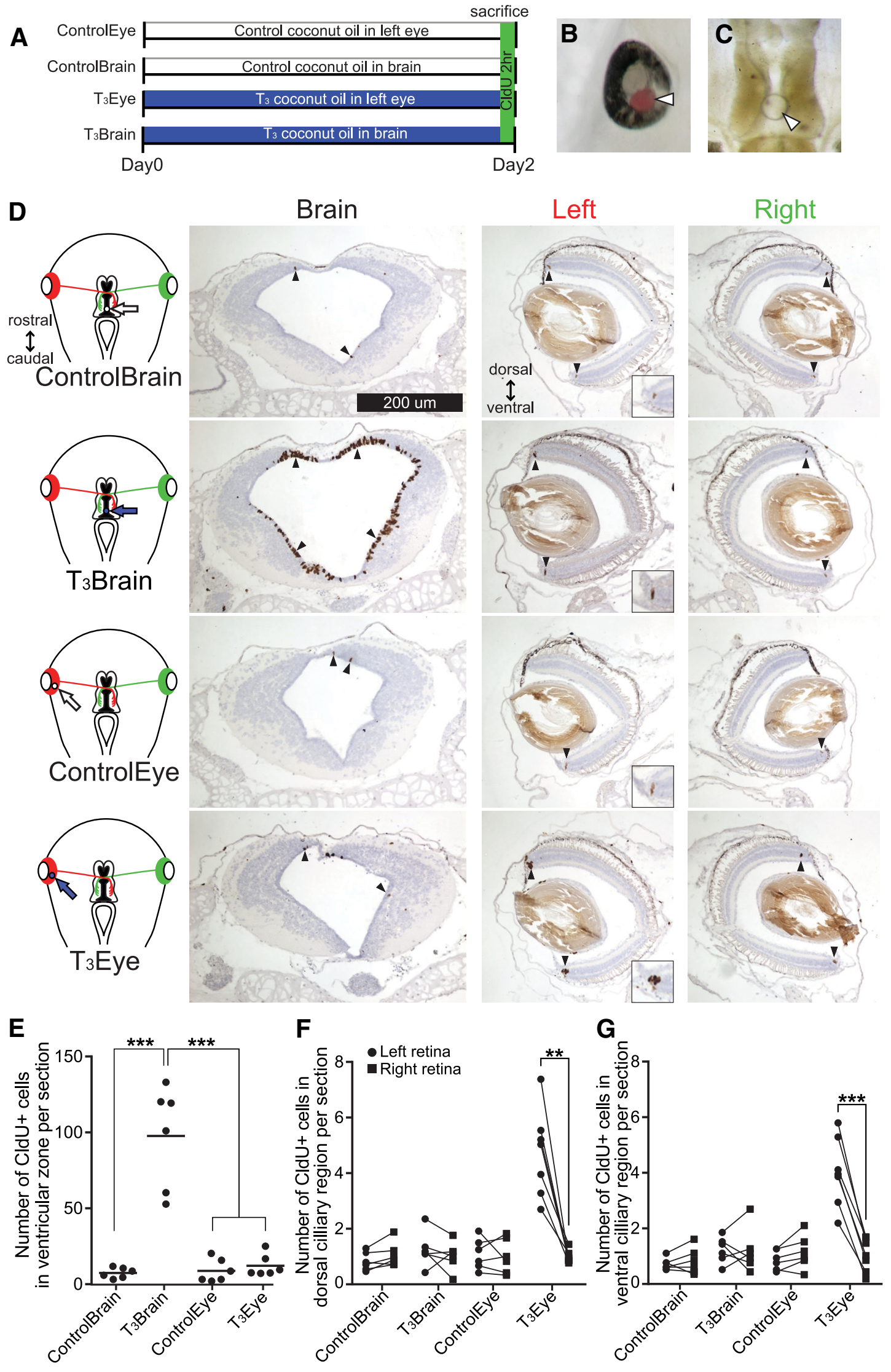

Figure 8. $T_{3}$ acts locally to increase cell proliferation in the retina and optic tectum. $A$, Timeline of experiment. $B, C$, Animals were treated with control coconut oil (ControlCO) or $T_{3} C 0$ injected into the left eye $(\boldsymbol{B})$ or into the midbrain ventricle near the tectum $(\boldsymbol{C})$. Arrowheads point to $C$. Note that the coconut oil in $\boldsymbol{B}$ is dyed with Oil Red 0 to enhance visibility. $\boldsymbol{D}$, Left column, Diagrams of local $\mathrm{C} 0$ treatments in the eye or brain. Arrows point to location of $\mathrm{C} O$ in the eye or tectum. Red and green mark left and right retinas and their projections, respectively. Right panels, Photomicrographs of sections through the head showing the brain and the eyes immunolabeled for CldU and counterstained with hematoxylin. Arrowheads point to CldU + cells in (Figure legend continues.) 
with the other day 10 treatment groups. Importantly, proliferation in the DIO3 MO/MMI treatment group was comparable with that seen with MMI alone. These data suggest that DIO3 knockdown increased local action of $\mathrm{TH}$, which is sufficient to increase proliferation. Furthermore, the data indicate that MMI treatment for $5 \mathrm{~d}$ is sufficient to decrease circulating levels of $\mathrm{TH}$, thereby decreasing proliferation, but pretreatment with MMI is required to decrease circulating $\mathrm{TH}$ sufficiently, so that DIO3 knockdown cannot increase local TH signaling and increase proliferation. Finally, qPCR showed that DIO3 MO significantly increased midbrain expression of nrep relative to control $\mathrm{MO}$ (DIO3 MO, $1.34 \pm 0.08$; control MO, $1.03 \pm 0.08$; Mann-Whitney $U$ test, $p<0.05, n=10$ per group), consistent with the idea that DIO3 MO increases proliferation by increasing local $\mathrm{TH}$ signaling. Together, the results show that endogenous TH regulates neurogenesis in the optic tectum long before the surge in endogenous levels of circulating $\mathrm{TH}$ that promotes metamorphosis. The results further indicate that increasing or decreasing endogenous $\mathrm{TH}$ signaling has corresponding effects on tectal cell proliferation, suggesting that the NPC proliferation rate may be homeostatically regulated by mechanisms that govern endogenous TH signaling.

To test the efficacy of morpholino-mediated knockdown of DIO3 expression, we used an in vivo imaging assay described by Faulkner et al. (2015) that can be used when specific antibodies against the target protein are not available. We electroporated optic tecta of stage 46 tadpoles with two plasmids: pSox2bd::Gal4/UAS::DIO3-t2A-eGFP and UAS::tRFPnls (Fig. $5 A$ ). Tadpoles were coelectroporated with either control MO or DIO3 MO. If DIO3 MO blocks translation of the DIO3-t2A-GFP transcript, then we expect to see a decrease in eGFP intensity in $\mathrm{RFP}+$ cells compared with control MO, and some cells may be $\mathrm{RFP}+$ with no detectable GFP. We measured eGFP intensity in tRFP + cells (Fig. $5 B, C$ ) and found that DIO3 MO significantly decreased eGFP expression compared with cells transfected with control MO (Fig. $5 D$; $t$ test, $p<0.01$ ). DIO3 MO treatment also significantly decreased the percentage of tRFP + cells that were $\mathrm{eGFP}+$ (Fig. $5 E$; $t$ test, $p<0.0001$ ).

Local delivery of $\mathrm{T}_{3}$ to the midbrain alters tectal morphology, cell proliferation, and cell death

Systemic exposure of tadpoles of the stages used in our studies to $50 \mathrm{nM} \mathrm{T}_{3}$ causes gross morphological effects, including changes in the shape of the mouth and head, shortened body length caused by premature tail resorption, and weight loss, because of impaired mobility and feeding behaviors and changes in the gut, consistent with previous studies showing differential spatiotemporal tissue-specific sensitivity to TH (Tata, 1968). These tadpoles typically do not survive longer than 7-10 d, likely because precocious $\mathrm{TH}$-induced changes to the mouth, gut, and lungs are not temporally coordinated with other metamorphic changes,

\footnotetext{
$\leftarrow$

(Figure legend continued.) the ciliary margin in the eye and proliferative zone in the brain. Insets at bottom right show increased magnification of CldU + cells in the ventral ciliary margin. $E, \mathrm{~T}_{3} \mathrm{CO}$ delivery to the brain ventricle significantly increased cell proliferation in the midbrain ventricular zone; local $\mathrm{T}_{3} \mathrm{CO}$ delivery in the eye did not affect proliferation in the midbrain. $F, G$, Comparisons of the numbers of CldU + cells in the ciliary margins of the left and right eyes for animals in the four experimental groups (schematized in $\boldsymbol{D}$, left). Data for dorsal $(\boldsymbol{F})$ and ventral $(\boldsymbol{G})$ ciliary margins are shown separately. $\mathrm{T}_{3} \mathrm{C} 0$ treatment in the left eye increased cell proliferation in dorsal $(\boldsymbol{F})$ and ventral $(\boldsymbol{G})$ ciliary margins of the left eye. The proliferation rate in the eye was not increased when $\mathrm{T}_{3} \mathrm{CO}$ was injected into the brain ventricle ( $G$; ANOVA and Tukey's post hoc test, $\left.{ }^{* *} p<0.01,{ }^{* * *} p<0.001\right)$.
}

such as limb development. To determine whether $\mathrm{T}_{3}$ mediates changes in tectal development by acting directly on tectal cells and to circumvent ambiguities arising from systemic $\mathrm{T}_{3}$ treatment, we adapted methods from previously published studies (Kaltenbach, 1970; Kaltenbach and Hobbs, 1972; Leatherland, 1987). We injected $T_{3}$ emulsified in coconut oil directly into the midbrain ventricle. To identify a concentration of $\mathrm{T}_{3} \mathrm{CO}$ that only affects the brain and not the rest of the body, we tested three concentrations of $\mathrm{T}_{3} \mathrm{CO}(5 \mathrm{mg} / \mathrm{ml}, 1 \mathrm{mg} / \mathrm{ml}, 500 \mu \mathrm{g} / \mathrm{ml})$ compared with two control groups: a group that was injected with ControlCO and a group that was not injected with $\mathrm{CO}$ (NoCO). We had a positive control group that was treated with $\mathrm{T}_{3}$ in Steinburg's solution. Tadpoles from each group were killed each day for $7 \mathrm{~d}$ to capture $\mathrm{T}_{3}$-mediated changes in tectal development. $\mathrm{T}_{3}$ in Steinberg's solution affected the whole tadpole, inducing changes in craniofacial features (e.g., extension of Meckel's cartilage; Fig. 6A) and a decrease in body length (Fig. 6B), consistent with previous work showing that $\mathrm{TH}$ acts throughout the tadpole body to induce restructuring of organs and tissues, including the brain (Denver, 1998; Shi, 2000). The two highest concentrations of $\mathrm{T}_{3} \mathrm{CO}(1$ and $5 \mathrm{mg} / \mathrm{ml})$ also significantly decreased body length and affected craniofacial features (Fig. 6A,B). By contrast, the body length and gross morphology of tadpoles injected with 500 $\mu \mathrm{g} / \mathrm{ml} \mathrm{T}_{3} \mathrm{CO}$ were not different from the ControlCO and NoCo groups (Fig. $6 A, B$ ).

We then dissected the brains from the tadpoles used for bodylength measurements (described above) and immunostained them for $\mathrm{pH} 3$ and Sytox-O (Fig. 7A). Measurements of the tectal width/length ratio showed that all doses of $\mathrm{T}_{3} \mathrm{CO}$ increased tectal size to a comparable extent (Fig. $7 B$ ), which was also similar to the increased tectal size seen in animals exposed to $\mathrm{T}_{3}$ in Steinberg's solution. The lowest dose of $\mathrm{T}_{3} \mathrm{CO}$ maintained an elevated NPC proliferation rate throughout the $7 \mathrm{~d}$ experiment but showed no increase in cell death (Fig. $7 C, D)$. The increase in apoptosis seen with 1 and $5 \mathrm{mg} / \mathrm{ml} \mathrm{T}_{3} \mathrm{CO}$, as well as with $\mathrm{T}_{3}$ in Steinberg's solution, may either be attributable to indirect systemic effects on feeding behaviors or gut function (Tata, 1968; Denver et al., 2009) or might be similar to increases in cell death that occur during metamorphosis (Kollros and Thiesse, 1985; Gona et al., 1988; Coen et al., 2007). The observation that local $500 \mu \mathrm{g} / \mathrm{ml} \mathrm{T}_{3} \mathrm{CO}$ induces changes in tectal morphology without affecting body morphology suggests that $\mathrm{T}_{3}$ is acting directly on the brain and that the changes in tectal morphology are not a result of non-neural side effects on the gut or elsewhere in the body. Together, the data in Figures 6 and 7 indicate that local injection of $500 \mu \mathrm{g} / \mathrm{ml} \mathrm{T}_{3} \mathrm{CO}$ into the midbrain ventricle will allow us to study the effect of local increases in tectal $\mathrm{T}_{3}$ on tectal development.

\section{$\mathrm{T}_{3}$ acts locally to increase cell proliferation in the retina and optic tectum}

During metamorphosis, $\mathrm{TH}$ acts directly on the retina, inducing asymmetric proliferation to reorient the eye upward (Kaltenbach and Hobbs, 1972; Hoskins and Grobstein, 1984, 1985a,b; Mann and Holt, 2001). $\mathrm{T}_{3}$-mediated effects in the tectum, reported above, may depend on afferent input from retinal ganglion cells. To test whether local $\mathrm{T}_{3}$ delivery to the eye or tectum affects neurogenesis in the tectum or retina, respectively, we injected either $\mathrm{T}_{3} 500 \mu \mathrm{g} / \mathrm{ml} \mathrm{CO}$ or ControlCO into the midbrain ventricle near the tectum or into the left eye (Fig. $8 A-C$ ). Tadpoles were killed after $2 \mathrm{~d}$, which is sufficient to detect increased proliferation in the tectal proliferative zone in response to $\mathrm{T}_{3}$ (Fig. $3 C$ ). Local delivery of $\mathrm{T}_{3} \mathrm{CO}$ into the midbrain ventricle increased the 

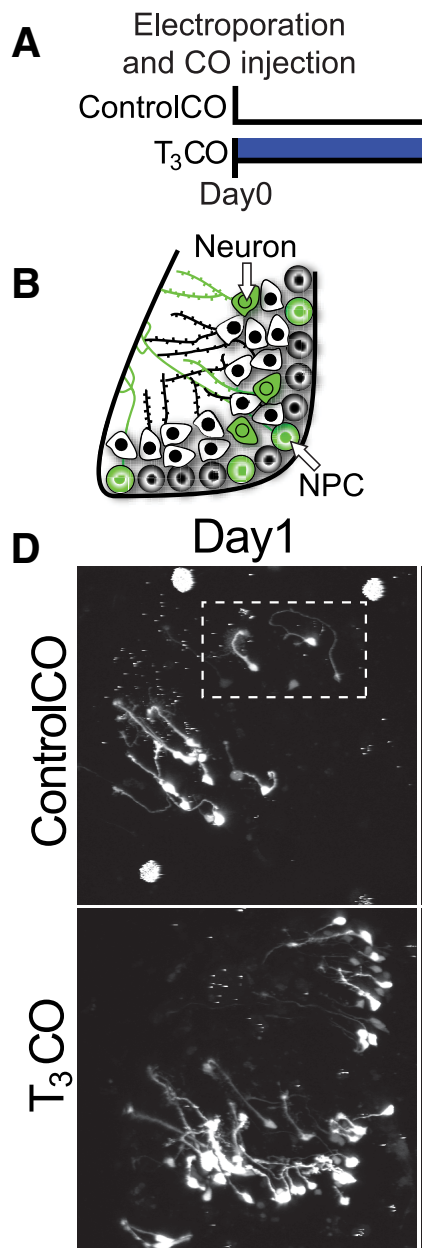

E

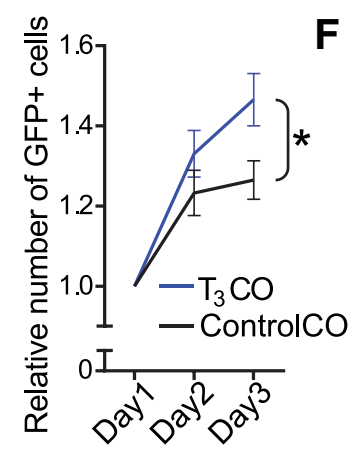

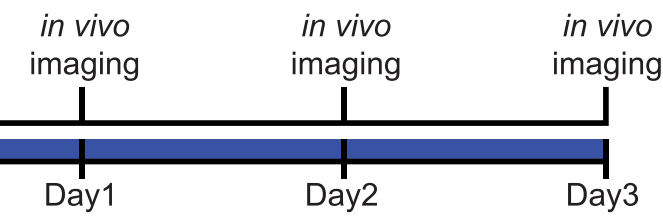
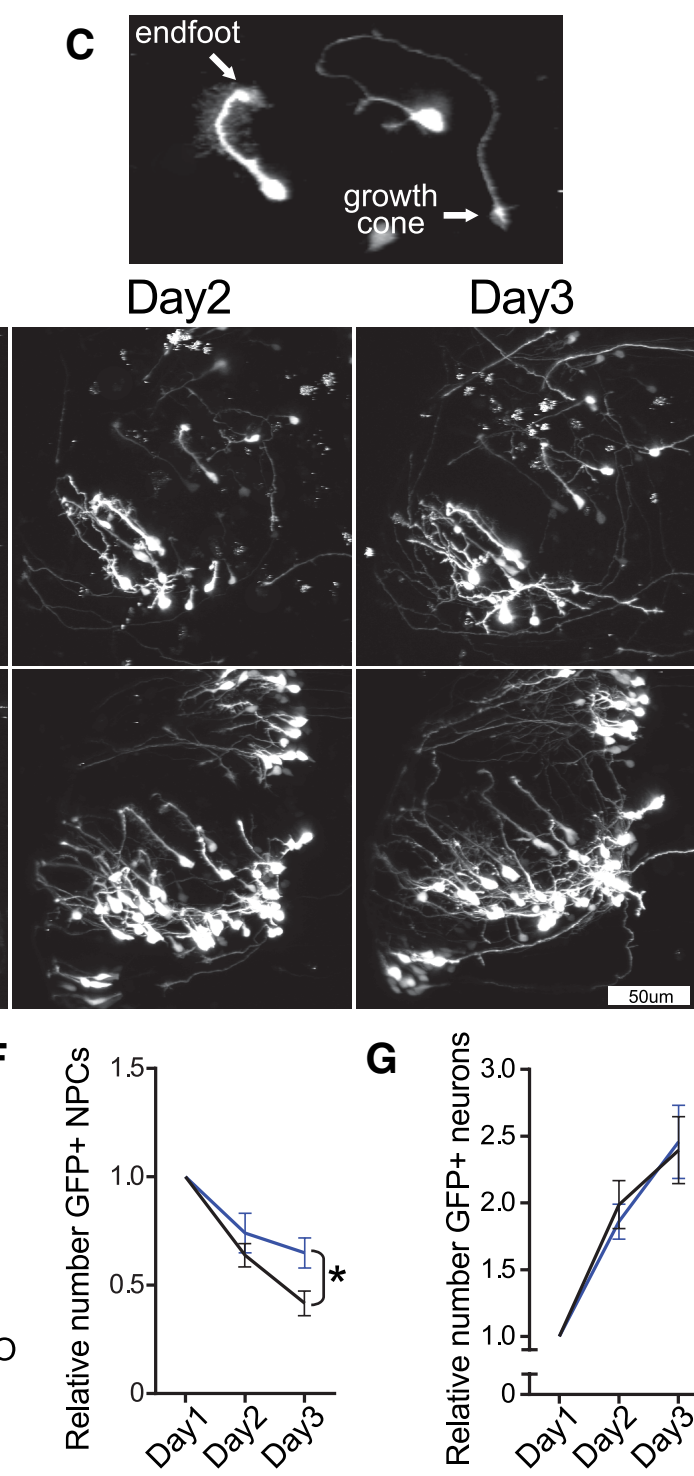

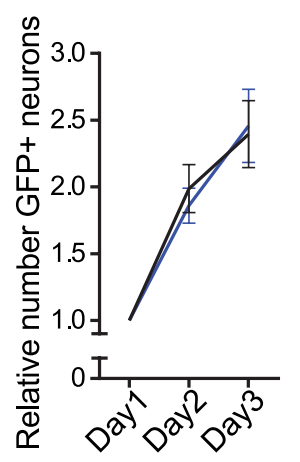

Figure 9. Local delivery of $\mathrm{T}_{3}$ expands the proliferative pool in the tectum. $\boldsymbol{A}$, Timeline of experiment. Brains were electroporated with Sox2bd::eGFP reporter plasmids, and the midbrain ventricle was injected with either ControlCO or $\mathrm{T}_{3} \mathrm{CO}(500 \mu \mathrm{g} / \mathrm{ml})$. Starting the following day, GFP + cells were imaged daily for $3 \mathrm{~d}$ in vivo on a two-photon microscope. $\boldsymbol{B}$, Schematic of the cellular makeup of the tadpole retinotectal circuit in the left hemisphere. Cells are randomly labeled with GFP, which spreads throughout the cell, including the processes. C, Still image of Movie 1. Two-photon z-projection of a NPC (left) and neuron (right). GFP + cells were counted and classified as NPCs or neurons based on morphology. NPCs have a distinctive endfoot adjacent to the pial surface of the brain and filopodia along the single process. Young neurons like the one illustrated here have dendritic arbors near the soma and an axon that projects through the tectum with a growth cone at the end. See Movie 1 for more detail. $\boldsymbol{D}$, Representative two-photon z-projections of images taken of the left tecta from tadpoles treated with ControlCO (top) or $\mathrm{T}_{3} \mathrm{CO}$ (bottom). $\boldsymbol{E}$, Plot of change in the relative total number of GFP + cells. $\mathrm{T}_{3} \mathrm{CO}$ significantly increased the number of GFP + cells by day 3 (repeated-measures ANOVA and Sidak's multiple comparison test, $\left.{ }^{*} p<0.05\right)$. $\boldsymbol{F}, \mathbf{G}$, Plot of change in the relative number of NPCs $(\boldsymbol{F})$ and neurons $(\boldsymbol{G})$. $\mathrm{T}_{3} \mathrm{CO}$ significantly increased the relative number of NPCs but did not affect the relative number of neurons over 3 days of treatment. $n=14-16$ tectal lobes pergroup.

number of CldU + cells in the proliferative zone in the midbrain compared with the control in which ControlCO was injected into the midbrain ventricle (Fig. $8 D$, E; ANOVA and Tukey's post hoc test, $p<0.001$ ). Furthermore, $\mathrm{T}_{3} \mathrm{CO}$ injection into the midbrain

ventricle did not affect CldU labeling in the retina, nor did $\mathrm{T}_{3} \mathrm{CO}$ injection into the eye affect proliferation in the brain. These results show that $\mathrm{T}_{3}$ acts directly in the optic tectum to stimulate proliferation.

Local delivery of $\mathrm{T}_{3} \mathrm{CO}$ into the left eye increased the number of CldU+ cells in the dorsal (Fig. 8F; paired $t$ test, $p<0.01$ ) and ventral (Fig. $8 G$; paired $t$ test, $p<$ 0.001 ) ciliary margins compared with the uninjected right eye. The fact that $\mathrm{T}_{3}$ increased proliferation in both the ventral and dorsal ciliary margins indicates that the retina of stage 47 tadpoles is not yet asymmetrically sensitive to the effects of $\mathrm{TH}$ signaling, as seen during metamorphosis (Hoskins and Grobstein, 1984, 1985a), possibly because DIO3 expression is not yet elevated in the dorsal retina, which dampens $T_{3}$ signaling in retina of older tadpoles (Marsh-Armstrong et al., 1999). These results further indicate that local delivery of $\mathrm{T}_{3}$ in coconut oil effectively limits $\mathrm{T}_{3}$ action to particular parts of a developing neural circuit, leaving other parts unaffected.

Local delivery of $\mathrm{T}_{3}$ expands the proliferative pool of NPCs in the tectum

Prior studies suggest that hyperthyroid rat pups have a transient increase in cell proliferation and that elevated $\mathrm{TH}$ signaling triggers NPCs in cerebellum to prematurely exit from the cell cycle and differentiate into neurons (Nicholson and Altman, 1972a). Our data in Figure 2 suggest that tectal NPCs continue to divide in the presence of $\mathrm{T}_{3}$. To directly test the effect of $\mathrm{T}_{3}$ on NPC proliferation and differentiation in vivo, we conducted in vivo time-lapse imaging experiments to determine the effects of local administration of $\mathrm{T}_{3}$ on cell proliferation and neuronal differentiation in tadpole tecta. We electroporated the optic tecta of stage 46 tadpoles with pSox2bd::GFP plasmids to express GFP in NPCs and their neuronal progeny (Bestman et al., 2012) and on the same day injected either ControlCO or $\mathrm{T}_{3} \mathrm{CO}$ into the midbrain ventricle (Fig. 9A). Starting the following day, we imaged the GFPexpressing NPCs and neurons at daily intervals for $3 \mathrm{~d}$ on a custom-built laserscanning two-photon microscope. This electroporation procedure sparsely labels NPCs in the ventricular zone with GFP, so their proliferation and differentiation into neurons can be visualized over subsequent days, while still maintaining sufficient levels of GFP for imaging (Bestman et al., 2012), as schematized (Fig. 9B) and illustrated in Figure $9 \mathrm{C}$ and Movie 1. Representative images of GFP-expressing NPCs and neurons are shown in single optic 


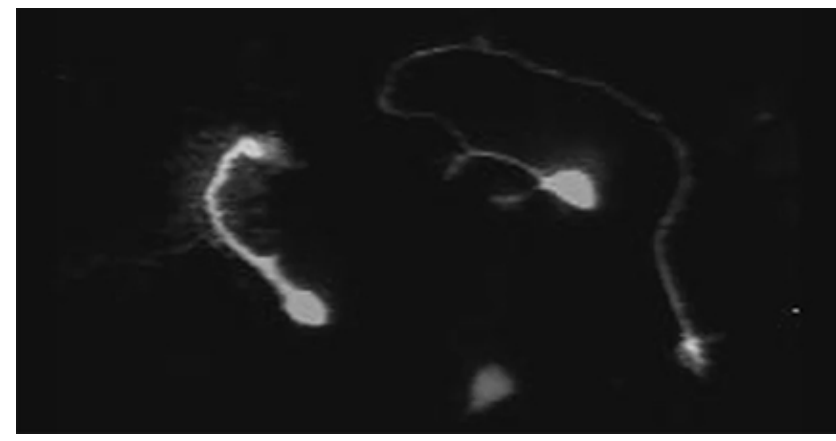

Movie 1. Two-photon z-projection of a NPC (left) and neuron (right). GFP + cells were counted and classified as NPCs or neurons based on morphology. NPCs have a distinctive endfoot adjacent to the dorsal surface of the brain and filopodia along the single process. Young neurons like the one illustrated here have dendritic arbors near the soma and an axon that projects through the tectum with a growth cone at the end. (Image from Fig. 9 C.)

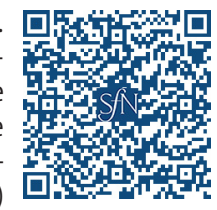

tectal lobes from animals treated with ControlCO or $\mathrm{T}_{3} \mathrm{CO}$ over $3 \mathrm{~d}$ of in vivo imaging (Fig. 9D). Increases in the numbers of GFP+ cells and increased complexity of neuronal dendrites and axons can be seen over the time course in control and $\mathrm{T}_{3} \mathrm{CO}$-treated tecta. $\mathrm{T}_{3} \mathrm{CO}$ significantly increased the total number of GFP+ cells by day3 (Fig. 9E; two-way repeated-measures ANOVA, $p<0.05$ ). Separate analyses of NPCs and neurons show that the increase occurred in the NPC population $(p<0.05)$ but not in the neuronal population (Fig. $9 F, G$ ). These data suggest that $\mathrm{T}_{3}$ expands the progenitor pool over the first $3 \mathrm{~d}$ of $\mathrm{T}_{3}$ exposure, without increasing neuronal differentiation.

\section{Local delivery of $T_{3}$ significantly increases optic tectal neuronal differentiation}

To determine how longer exposures to $\mathrm{T}_{3}$ change tectal cell fate, we injected stage 46 tadpole midbrain ventricles with either ControlCO or $\mathrm{T}_{3} \mathrm{CO}$ and then electroporated them $6 \mathrm{~d}$ later (late stage 47 to early stage 48) with pSox2::GFP plasmids. We collected in vivo twophoton time-lapse images of the tecta once per day over the following $3 \mathrm{~d}$ (Fig. 10A). Representative images of control and $\mathrm{T}_{3} \mathrm{CO}$ treated tectal lobes are shown in Figure $10 \mathrm{C}$ over the $3 \mathrm{~d}$ time course of the experiment. Quantitative analysis showed that the number of GFP+ cells did not vary between the two groups over the $3 \mathrm{~d}$ of imaging (Fig. 10D), but distinguishing NPCs from neurons showed that the relative numbers of NPCs significantly decreased over $3 \mathrm{~d}$ in tecta treated with $\mathrm{T}_{3} \mathrm{CO}$ (Fig. 10E; two-way repeated-measures ANOVA, $p<0.05$ ), and there is a corresponding increase in GFP+ neurons (Fig. 10F; $p<0.05$ ). $\mathrm{T}_{3} \mathrm{CO}$ increased the proportion of GFP + cells that were neurons relative to controls, even on the first day of imaging after $24 \mathrm{~h}$ of $\mathrm{T}_{3} \mathrm{CO}$ treatment. Furthermore, the relative proportion of neurons in the tecta treated with $\mathrm{T}_{3} \mathrm{CO}$ continued to increase over the next $2 \mathrm{~d}$ of imaging (Fig. 10G). The relative increase in neurons was balanced by a corresponding decrease in the proportion of NPCs, as the NPCs change fate and differentiate into neurons. The time-lapse imaging data in Figures 9 and 10 suggest that $\mathrm{T}_{3}$ initially promotes NPC proliferation and after a delay promotes NPCs to exit the cell cycle and differentiate into neurons. The data also suggest that under control conditions the relative rate of differentiation of NPCs into neurons is lower than in the presence of $\mathrm{T}_{3}$.

We also analyzed the effect of $\mathrm{T}_{3} \mathrm{CO}$ on differentiation by immunolabeling for $\mathrm{HuC} / \mathrm{D}$, a neuron-specific marker, in GFPexpressing cells after pSox 2 bd::GFP electroporation, using the experimental protocol shown in Figure 11A. Animals were injected in the midbrain ventricle with ControlCO or $\mathrm{T}_{3} \mathrm{CO}$. Six

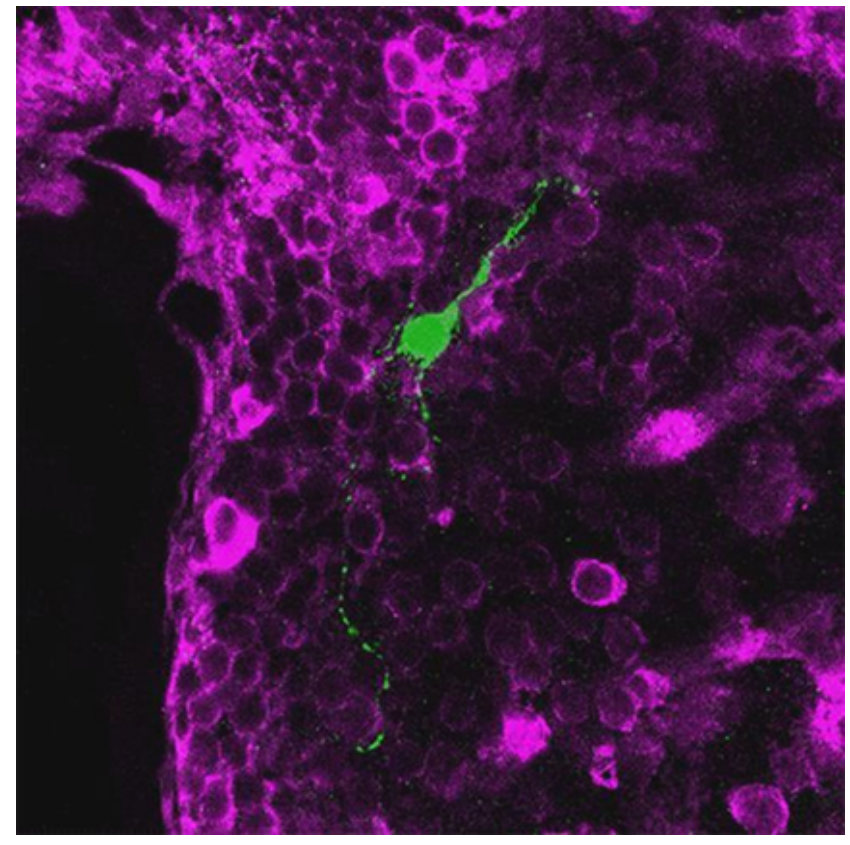

Movie 2. GFP + neurons were positive for HuC/D immunolabel whereas GFP + NPCs were HuC/D negative and located in the HuC/ $D$-free proliferative zone.

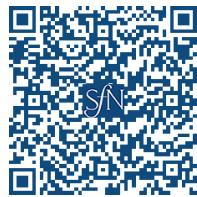

days later, optic tecta were electroporated with pSox2bd::GFP, and animals were killed after $3 \mathrm{~d}$ and immunolabeled for $\mathrm{HuC} / \mathrm{D}$ and GFP. Representative confocal images of tecta treated with ControlCO or $\mathrm{T}_{3} \mathrm{CO}$ are shown in Figure $11 \mathrm{~B}$. We identified $\mathrm{GFP}+$ cells that were $\mathrm{HuC} / \mathrm{D}$ positive, as neurons (Fig. $11 \mathrm{C}$ and Movie 2), and GFP+ cells along the ventricle that were $\mathrm{HuC} / \mathrm{D}$ negative as NPCs (Fig. 11D). $\mathrm{T}_{3} \mathrm{CO}$ increased the proportion of $\mathrm{GFP}+$ cells that were $\mathrm{HuC} / \mathrm{D}+$ (i.e., neurons) relative to the ControlCOs (Fig. 11E; $p<0.01$ ), corroborating the observations from the in vivo imaging experiments. Together, the experiments in Figures 9-11 indicate that local delivery of $\mathrm{T}_{3}$ to the midbrain rapidly expands the progenitor pool and subsequently enhances differentiation of NPCs into neurons.

\section{$\mathrm{T}_{3}$ treatment increases dendritic arborization in tectal neurons}

Optic tectal neurons typically elaborate complex dendritic arbors over $5 \mathrm{~d}$, after which arbor growth rate stabilizes ( $\mathrm{Wu}$ and Cline, 1998; He et al., 2016). Our data show that $\mathrm{T}_{3}$ treatment induces a change in tectal morphology $4 \mathrm{~d}$ after onset of treatment (Figs. 1, 7), suggesting that $\mathrm{TH}$ may have a rapid effect on neuronal structure. To assess whether structurally stable dendritic arbors are sensitive to $T_{3}$, we sparsely electroporated optic tecta of stage 46 tadpoles with p-actinin::GAL4/UAS::eGFP to label NPCs and $6 \mathrm{~d}$ later collected in vivo time-lapse two-photon images of GFP-labeled neurons using the protocol shown in Figure 10A. Immediately after collecting the first image, the animals were divided into two groups, and the midbrain ventricle was injected with either ControlCO or $\mathrm{T}_{3} \mathrm{CO}$. Tecta were then imaged at daily intervals over the following $3 \mathrm{~d}$ (Fig. 12A). Representative images and reconstructions of neurons from ControlCO- and $\mathrm{T}_{3} \mathrm{CO}$-treated tecta are shown in Figure 12B. Total dendritic branch length on day 0 did not differ significantly between the two groups (ControlCO, $627 \pm 46 \mu \mathrm{m} ; \mathrm{T}_{3} \mathrm{CO}, 511 \pm 100 \mu \mathrm{m}$; $t$ test, 
A

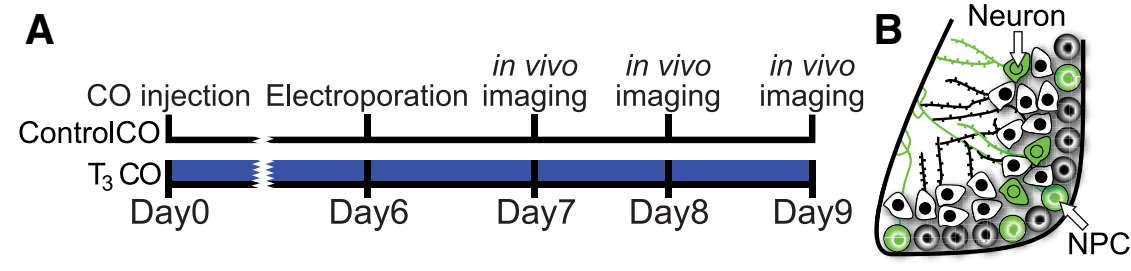

C
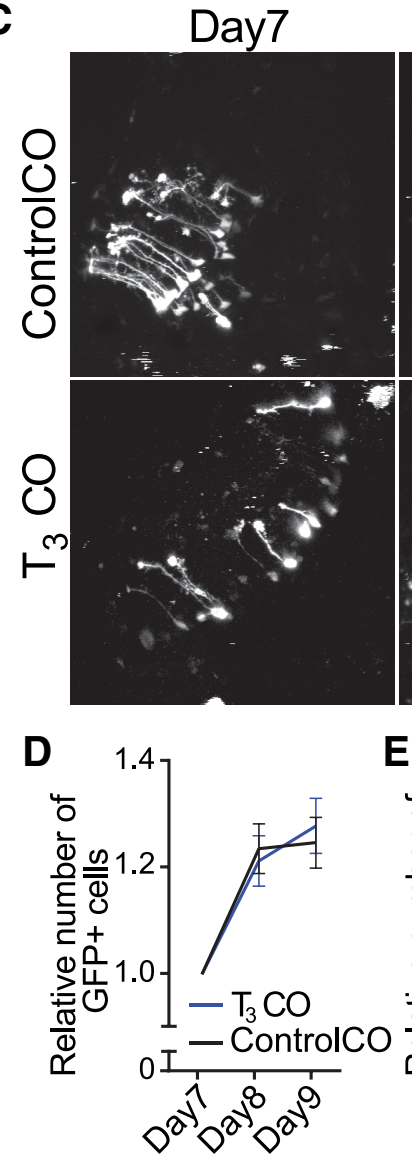

E
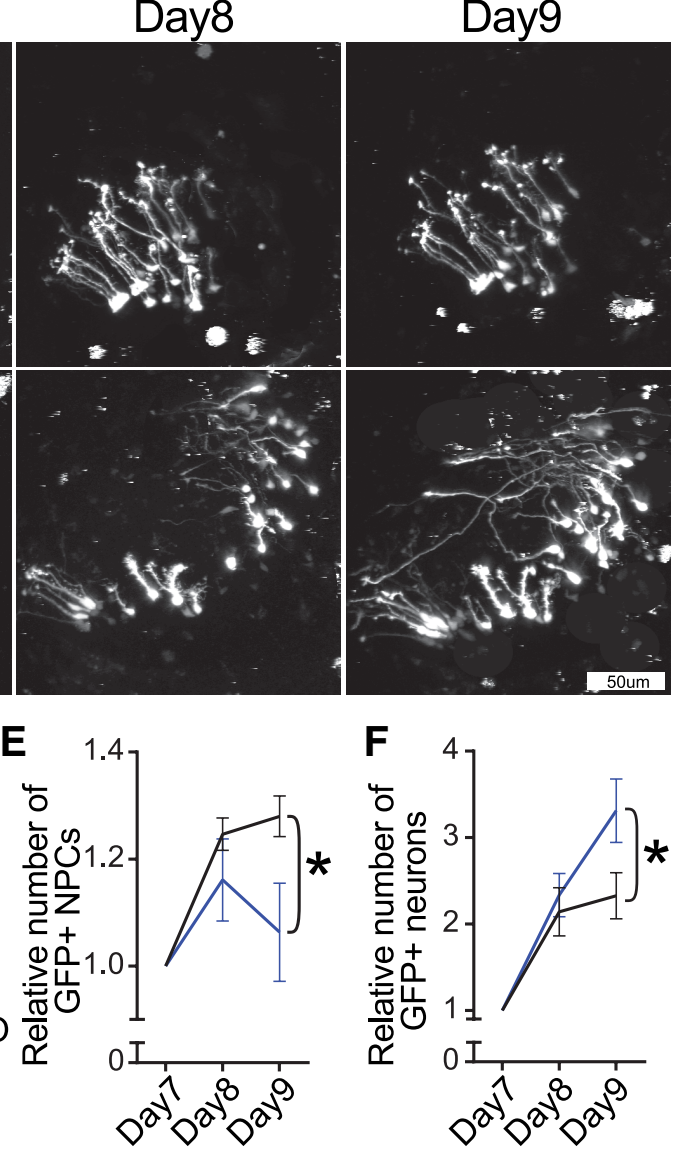

$\mathbf{F}$

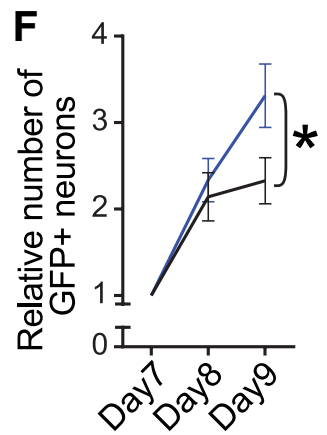

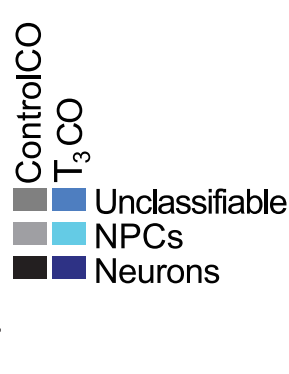

Figure 10. Local delivery of $T_{3}$ increases neuronal differentiation. $\boldsymbol{A}$, Timeline of experiment. The midbrain ventricle was injected with either ControlCO or $\mathrm{T}_{3} \mathrm{CO}(500 \mu \mathrm{g} / \mathrm{ml})$. After $6 \mathrm{~d}$, brains were electroporated with GFP reporter plasmids. GFP + cells were imaged in vivo on a two-photon microscope daily for $3 \mathrm{~d}$. $\boldsymbol{B}$, Schematic of the cellular makeup of the tadpole retinotectal circuit in the left hemisphere. Cells are randomly labeled with GFP, which spreads throughout the cell, including the processes. $C$, Z-projections of images taken of the left tecta from tadpoles treated with ControlCO (top) or $\mathrm{T}_{3} \mathrm{CO}$ (bottom). GFP + cells were counted and classified as NPCs or neurons. $\boldsymbol{D}$, The number of GFP + cells was comparable in $\mathrm{T}_{3} \mathrm{C} 0$-treated ( $n=14$ tecta) and ControlC0-treated ( $n=16$ tecta) animals over the $3 \mathrm{~d}$ of imaging. $\boldsymbol{E}, \boldsymbol{F}$, Plot of change in the relative number of NPCS $(\boldsymbol{E})$ and neurons $(\boldsymbol{F})$ over 3 days in vivo. $T_{3} \mathrm{CO}$ significantly decreased the relative number of NPCs and increased the relative number of neurons on day 3 compared with controls. $G, \mathrm{~T}_{3} \mathrm{CO}$ increased the proportion of GFP + cells that were neurons compared with ControlC 0 on all 3 d examined (repeated-measures ANOVA and Sidak's multiple comparison test, ${ }^{*} p<0.05$ ).

$p=0.28)$ and was comparable with that seen in prior studies (Nedivi et al., 1998; Wu and Cline, 1998; Chiu et al., 2008). The sample control neuron has a complex dendritic arbor on the first day of imaging, and the arbor structure remains relatively stable over the next $3 \mathrm{~d}$ of imaging in vivo. By contrast, the representative $\mathrm{T}_{3} \mathrm{CO}$ neuronal arbor was also complex at the first image, before $\mathrm{T}_{3} \mathrm{CO}$ treatment, but dramatically increased dendritic arbor complexity over the following $3 \mathrm{~d}$ of imaging during exposure to $\mathrm{T}_{3}$. Quantification of dendritic branch tip numbers and total dendritic branch length showed that $\mathrm{T}_{3} \mathrm{CO}$ increased in dendritic branch tip number (Fig. 12C) and total dendritic arbor length (Fig. 12D), so they were significantly greater than controls on days 2 and 3 after $\mathrm{T}_{3} \mathrm{CO}$ treatment. These results show that tectal neurons with structurally stable dendritic arbors respond to local increases in $\mathrm{T}_{3}$ by rapidly increasing dendritic arbor complexity.

\section{$T_{3}$ induces changes in gene expression pertaining to proliferation and differentiation}

The results above indicate that $\mathrm{T}_{3}$ treatment increases tectal cell proliferation and neuronal differentiation and enhances dendritic arbor growth even in relatively stable neurons. TH treatment induces the expression of hundreds of genes in the brains of stage 52-54 Xenopus tadpoles (Denver et al., 1997; Das et al., 2006). We tested whether $\mathrm{T}_{3}$ changes the expression of genes known to affect aspects of proliferation and neuronal differentiation by performing qPCR on mRNA extracted from brains taken from tadpoles treated with $\mathrm{T}_{3}(50 \mathrm{nM})$ in Steinberg's solution for 2 or $4 \mathrm{~d}$ or controls, as schematized in Figure $13 \mathrm{~A}$. First, we evaluated five potential reference genes using two-way ANOVA across hormone treatment and time, as described in Materials and Methods. The percentage difference in expression for each potential reference gene in $\mathrm{T}_{3^{-}}$ treated tadpole brains was higher than the control at both time points (Table 2), but only three of these genes (gapdh, ywhaz, hprt1) were significantly affected by $\mathrm{T}_{3}$. Expression of the two other genes (rps13 and rpl32) was significantly affected by time, as was expression of $y$ whaz. We examined the stability of the genes using two analysis tool packages available for Excel. Both analyses suggested that all five genes were relatively stable, with geNorm $\mathrm{M}$ values $<1$ and NormFinder stability values $<0.1$. Thus, all the potential reference genes tested in this study had similar stability. Given that our primary interest was to identify differences in gene expression in response to hormone treatment, we used $r p s 13$ and $r p l 32$, because they showed no significant effect of $\mathrm{T}_{3}$ treatment on their expression.

We examined the effects of time and hormone treatment on expression of eight genes using the comparative $\Delta \Delta \mathrm{Ct}$ method 
with the average expression of rps13 and $r p l 32$ as a reference. Expression of $t r \alpha$ followed a significant interaction effect, with $\mathrm{T}_{3}$ inducing a marginal increase in expression on day 2 and a marginal decrease in expression on day4 (Fig. 13A). It has been previously shown that $4 \mathrm{~d}$ of $\mathrm{T}_{3}$ treatment decreases tr $\alpha$ expression in Xenopus tropicalis tadpole brains (DuarteGuterman and Trudeau, 2010). $\mathrm{T}_{3}$ treatment increased expression of $\operatorname{tr} \beta$ approximately threefold on both day 2 and day 4 relative to control (Fig. 13B). $\mathrm{T}_{3}$ treatment increased the expression of nrep, which is highly expressed throughout rat prenatal brain tissue and in adult brains in the subgranular zone in the dentate gyrus and in the subventricular zone (Studler et al., 1993). nrep expression increased sixfold and eightfold on days 2 and 4, respectively (Fig. 13C). $\mathrm{T}_{3}$ also increased expression of proliferating cell nuclear antigen (pcna) and minichromosome maintenance complex component 5 ( $m c m 5$; Fig. $13 C)$, both of which are increased in proliferating cells (Maga and Hubscher, 2003; Ryu and Driever, 2006). This suggests that $T_{3}$ activates the molecular pathways necessary for increased neuronal proliferation, consistent with experiments described above. Also of note is that expression of pcna and $m c m 5$ in the control groups significantly decreased from day 2 to day 4 , consistent with the decrease in proliferation seen over this interval in control animals (Sharma and Cline, 2010), and in the presence of $\mathrm{T}_{3}$ (Figs. 3C, 4D). We also examined the expression of putative reference genes. As mentioned above, two-way ANOVA showed that gapdh, ywhaz, and hprt1 all significantly increased expression in response to $\mathrm{T}_{3}$ treatment (Table 2); however, post hoc analysis indicated that significant differences between groups were only observed for expression of ywhaz and hprt1 (Fig. 13D). It is possible that changes in expression of these genes are related to their regulation of cellular metabolism. $\mathrm{T}_{3}$-induced increase in gapdh expression has been reported in brains of Silurana tropicalis tadpoles (Duarte-Guterman and Trudeau, 2010). These data show that exogenous treatment with $\mathrm{T}_{3}$ induces substantial changes in gene expression, including genes that regulate $\mathrm{TH}$ signaling $(\operatorname{tr} \beta)$, neurite outgrowth ( $n r e p)$, and proliferation (pcna and $m c m 5)$ and even genes that are typically used for reference ( $g a p d h, y w h a z, h p r t 1)$.

\section{Discussion}

Our data lead to three major conclusions regarding where and when TH acts on developing brain cells. First, the brain is sensiper group.
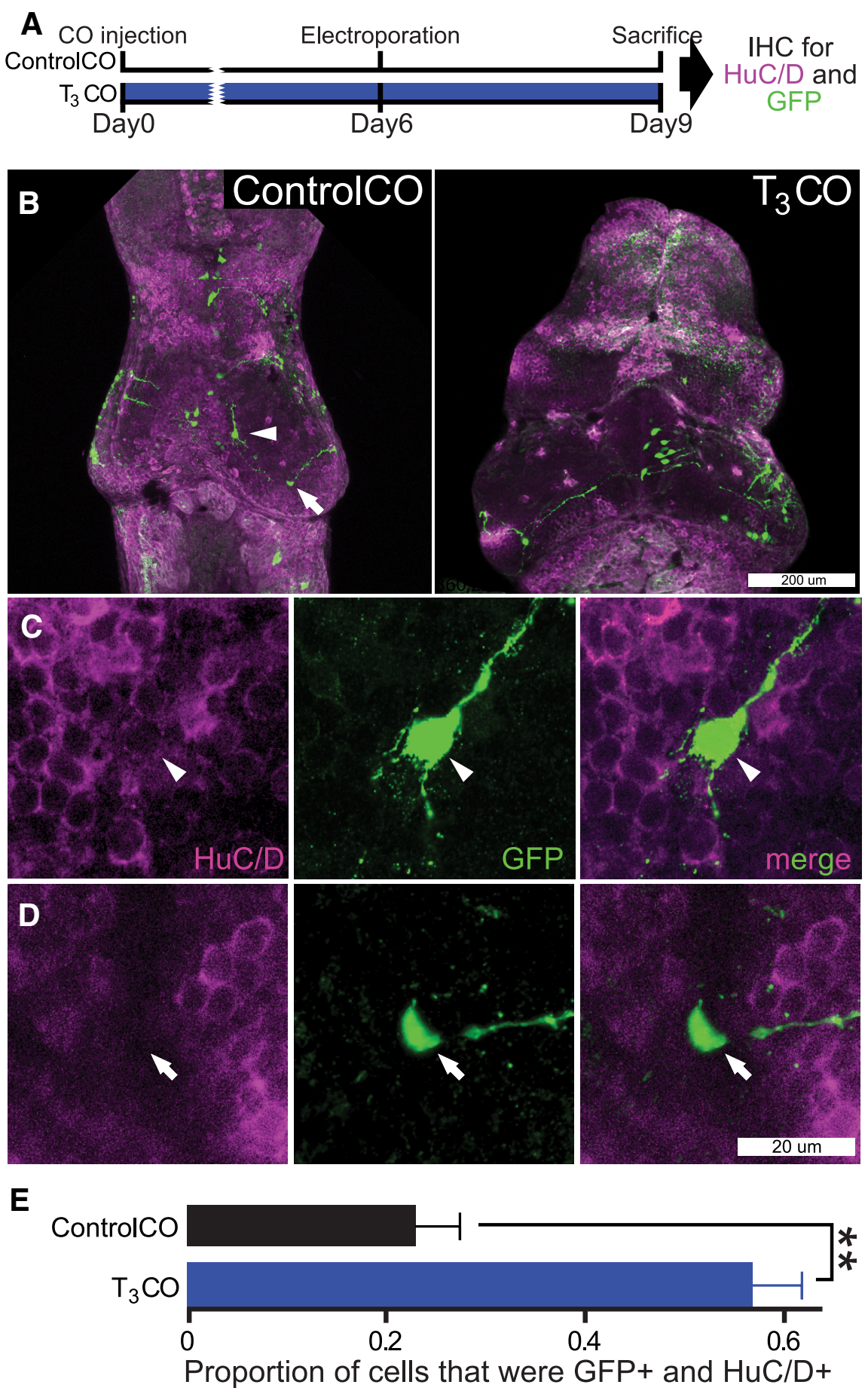

Figure 11. Local delivery of $\mathrm{T}_{3}$ increases tectal cell differentiation. $\boldsymbol{A}$, Timeline of experiment. The protocol was similar to the experiment in Figure 10, except that tectal neuronal differentiation was evaluated using immunohistochemical labeling (IHC) for HuC/D, a neuron-specific marker (purple), and for GFP (green). $\boldsymbol{B}$, Confocal z-projections of representative tecta from the ControlCO and $\mathrm{T}_{3} \mathrm{CO}$ groups. C, D, GFP + neurons were positive for HuC/D immunolabel (C, arrowhead), whereas GFP + NPCs were HuC/D negative ( $\boldsymbol{D}$, arrow) and located in the HuC/D-free proliferative zone. See Movie 2. $\boldsymbol{E}$, Local $\mathrm{T}_{3} \mathrm{CO}$ treatment increased the proportion of neurons (GFP + and $\mathrm{Hu}+; t$ test, $\left.{ }^{* *} p<0.01\right) . n=18-19$ tecta hemispheres

tive to increases in TH signaling at developmental stages when functional neural circuits are first forming. Second, local TH signaling rapidly alters the fate of NPCs by initially expanding the tectal progenitor pool and then increasing NPC differentiation into neurons. Third, increased TH signaling enhances dendritic arbor elaboration in differentiated neurons. Together, these data 

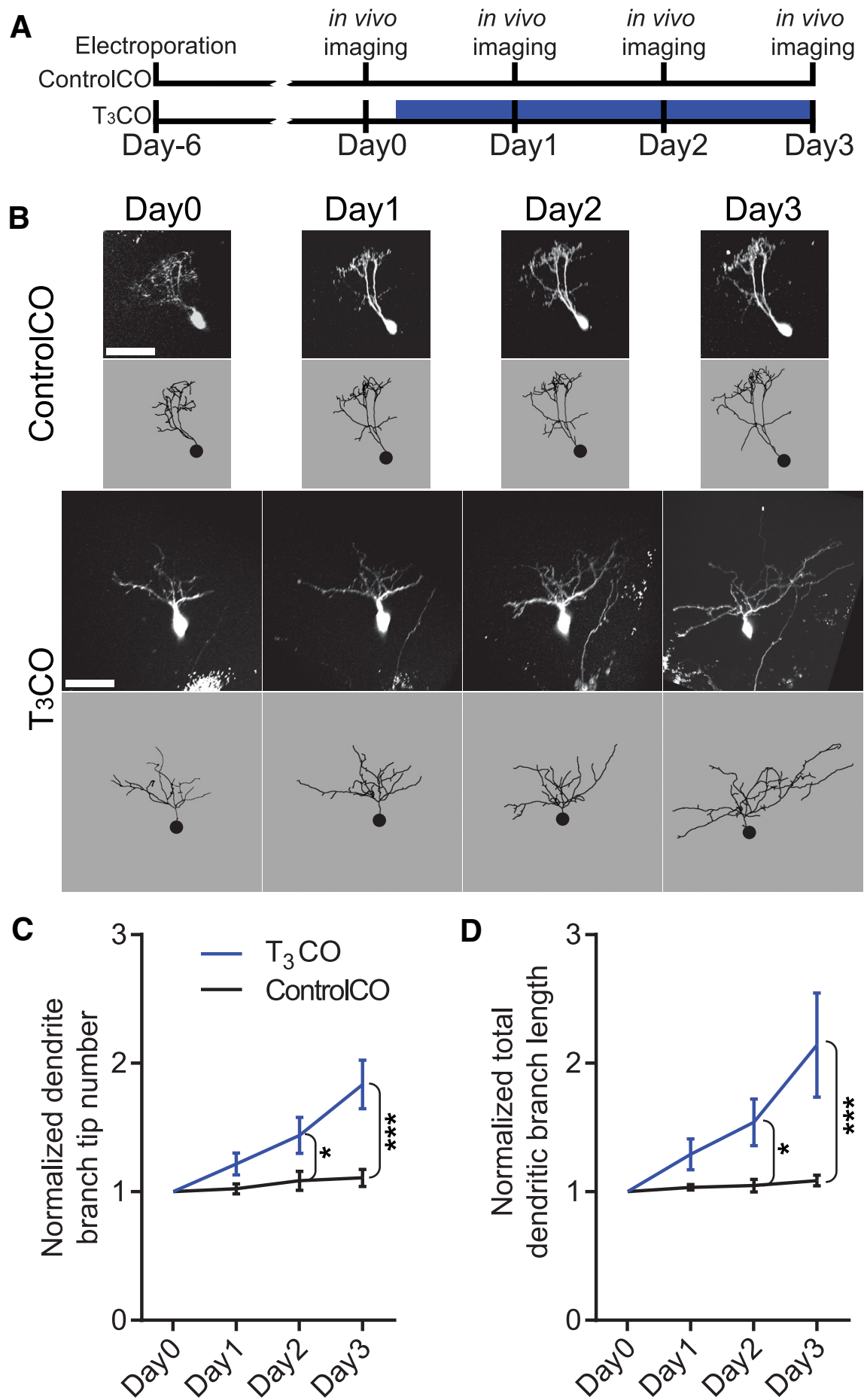

Figure 12. Local $\mathrm{T}_{3}$ treatment increases tectal cell dendritic arbor elaboration. $\boldsymbol{A}$, Timeline of experiment. Brains were sparsely electroporated with GFP reporter plasmids. After $6 \mathrm{~d}$, two-photon images of individual GFP + neurons were collected as a baseline. The midbrain ventricle was then injected with either Control $\mathrm{CO}$ or $\mathrm{T}_{3} \mathrm{CO}(500 \mu \mathrm{g} / \mathrm{ml})$, and GFP + neurons were imaged daily for the following 3 d. B, Z-projections (top) and dendritic arbor reconstructions (bottom) of GFP + tectal cells treated with ControlCO or $\mathrm{T}_{3}$ CO. Scale bar, $50 \mu \mathrm{m}$. C, $\boldsymbol{D}, \mathrm{T}_{3} \mathrm{CO}$ significantly increased dendritic branch tip number $(\boldsymbol{C})$ and total dendritic arbor branch length (D) over the $3 \mathrm{~d}$ of imaging. Data are normalized to day 0 (repeated-measures ANOVA and Sidak's multiple comparison test, ${ }^{*} p<$ $\left.0.05,{ }^{* *} p<0.001\right) . n=7-11$ arbors per group.

show that endogenous TH locally regulates cell fate and neuronal development during early brain development.

Several lines of evidence indicate that $\mathrm{TH}$ regulates multiple aspects of neurogenesis, including cell proliferation, survival, migration, and neuronal differentiation in the later stages of mammalian brain development, as shown in rodent cerebellum, hippocampus, and cortical structures (Legrand, 1979; Madeira et al., 1991; Martinez-Galan et al., 1997, 2004; Mohan et al., 2012; Nicholson and Altman, 1972a,b,c). The spatial and temporal aspects of $\mathrm{TH}$ signaling are controlled by mechanisms that regulate $\mathrm{TH}$ bioavailability, including changes in DIO3 expression (Chatonnet et al., 2011; Peeters et al., 2013). Our experiments specifically address the question of whether $\mathrm{TH}$ signaling affects neurogenesis at relatively early stages of brain development when circuits are first assembling. Global increases in $\mathrm{TH}$ signaling widely affect tadpole morphology, with different tissues and different brain regions showing differential sensitivity to $\mathrm{TH}$, as previously reported (Tata, 1968). This brain region-specific sensitivity to TH likely reflects local regulation of mechanisms controlling $\mathrm{TH}$ signaling. Our data show that both global and local increases in TH signaling increased tectal cell proliferation by expanding the pool of NPCs and that blocking endogenous $\mathrm{TH}$ production with MMI reduced tectal cell proliferation. These observations show that tectal cell proliferation at these early stages of development is sensitive to local changes in $\mathrm{TH}$ signaling and that dysregulation of endogenous $\mathrm{TH}$ signaling affects NPC proliferation in the CNS. Furthermore, increased TH signaling counteracts the normal decrease in tectal cell proliferation between stages 46 and 48 (Sharma and Cline, 2010). The TH-induced expansion of the proliferative pool occurs by increasing the number of cell divisions of each NPC, indicated by dilution of CldU label in $\mathrm{T}_{3}$-treated tadpole brains (Nicholson and Altman, 1972a; Denver et al., 2009).

The $\mathrm{T}_{3}$-induced expansion of the progenitor pool does not lead to an immediate increase in neurons. We combined local delivery of $\mathrm{T}_{3}$ with time-lapse in vivo imaging experiments, in which we follow the fate of GFP-labeled NPCs for periods over $9 \mathrm{~d}$ of local $\mathrm{T}_{3}$ exposure. This showed a rapid increase in NPCs in response to $T_{3}$, with no change in neuron number over the first $3 \mathrm{~d}$ of treatment, followed by a decrease in the proportion of GFP + NPCs and an increase in the proportion of GFP+ neurons between 7 and $9 \mathrm{~d}$ after the onset of treatment. The delayed effect on differentiation suggests that $\mathrm{T}_{3}$ affects NPC fate differently over time; initially $\mathrm{T}_{3}$ maintains NPCs in the cell cycle, after which $\mathrm{T}_{3}$ triggers a change in cell fate to generate differentiated neurons. The mechanisms underlying the different responses of tectal NPCs to TH over time remain to be elucidated.

Hyperthyroidism affects dendritic arbor growth in mammalian neurons, as is well documented in Purkinje cells both 

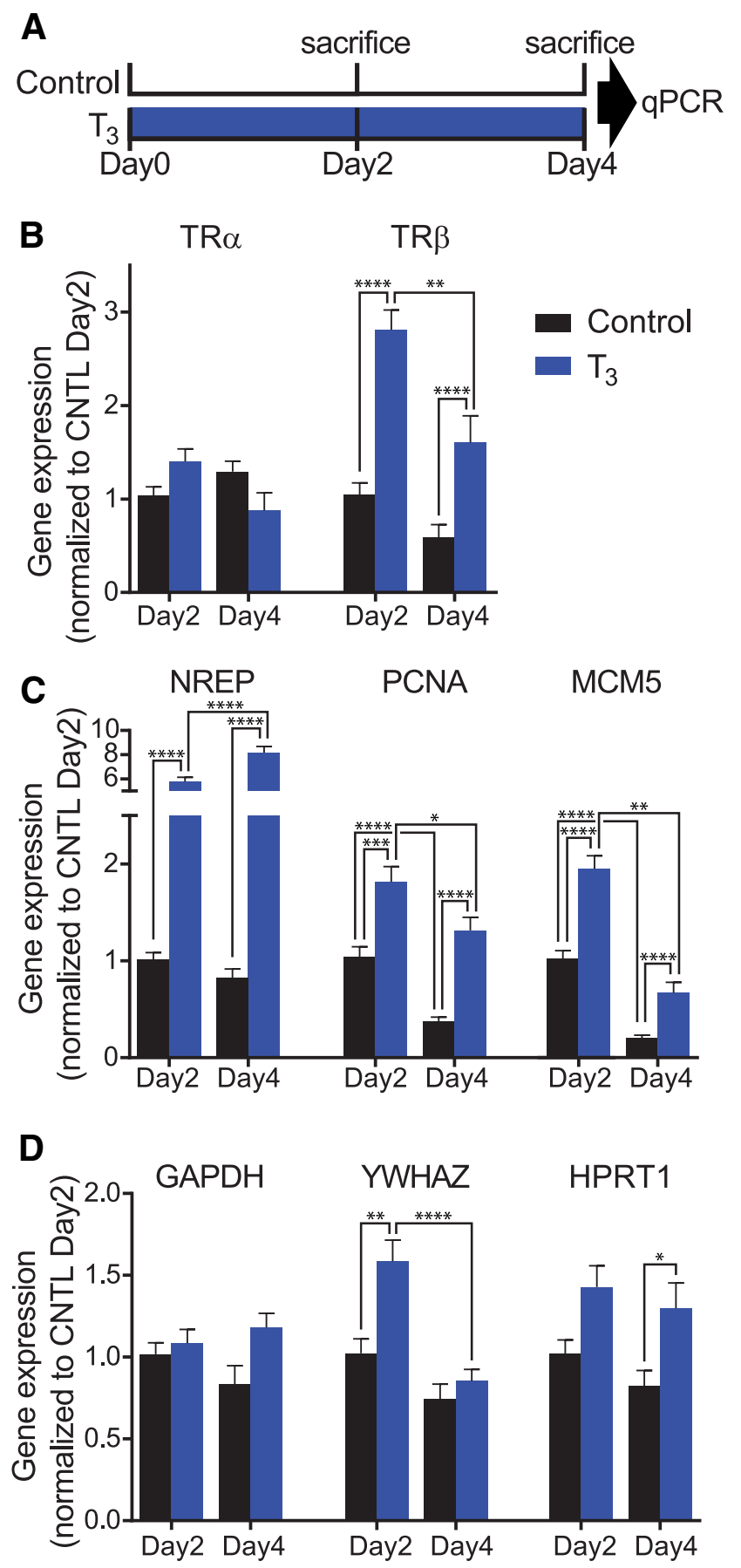

Figure 13. $T_{3}$ induces genes relevant to TH signaling and brain development. $A$, Tadpoles were placed into either control bath or $\mathrm{T}_{3}$ bath for either 2 or $4 \mathrm{~d}$ and $\mathrm{kill}$ led. mRNA was extracted from brains and analyzed via qPCR. $\boldsymbol{B}$, Two-way ANOVA showed a significant interaction effect for time and treatment for tr $\alpha$ expression, but post hoc analysis did not return specific differences between groups. $T_{3}$ treatment significantly increased tr $\beta$ expression on days 2 and 4 relative to controls. $C, T_{3}$ treatment significantly increased expression of nrep, pcna, and $m c m 5$ on days 2 and 4 relative to control. Also of note is that expression of $p c n a$ and $m c m 5$ in control bath tadpoles significantly decreased from day 2 to day 4. D, Two-way ANOVA showed a significant interaction effect for hormone treatment; $\mathrm{T}_{3}$ treatment increased expression of putative reference genes gapdh, ywhaz, and nrpt 1 relative to control. Post hoc analysis showed significant differences between specific groups for expression of $y$ whaz and $n r p t 1 . n=8$ brains per group.

in vivo and in vitro (Nicholson and Altman, 1972b; Legrand, 1979; Heuer and Mason, 2003; Koibuchi, 2013). Furthermore, treatment of hypothyroid animals with $\mathrm{TH}$ increases dendritic arbor growth (Legrand, 1979). Our in vivo imaging demon- strated that $\mathrm{T}_{3}$ treatment increased dendritic arborization nearly twofold in tectal neurons that were already $6 \mathrm{~d}$ old, which normally have relatively stable arbors ( $\mathrm{Wu}$ and Cline, 1998; He et al., 2016). Many studies have demonstrated a correlation between increased dendritic arbor complexity and increased synaptic inputs. For instance, electron microscopic studies have shown that virtually all terminal dendritic branches in optic tectal neurons receive synaptic inputs (Li et al., 2011), and electrophysiological studies show that mature tectal neurons with complex dendritic arbors have more synaptic inputs (Wu et al., 1996; Niell et al., 2004; Akerman and Cline, 2006; Haas et al., 2006; Sanchez et al., 2006; Shen et al., 2009, 2011). Together, these studies suggest that the $\mathrm{T}_{3}$ mediated increase in dendritic arborization may correlate with increased synaptic connectivity within the tectal circuit. Another interesting possibility is that the $\mathrm{TH}$-mediated increase in tectal cell dendrite arbor size may retrogradely increase elaboration of retinal ganglion cell axon arbors, similar to the effects of CPG15 expression in tectal neurons (Cantallops et al., 2000). Therefore, TH signaling is expected to affect several aspects of retinotectal circuit function that are sensitive to dendritic arbor size and synaptic connectivity, including the size of visual receptive fields, visual information processing and visually guided behavior, as well as multisensory integration (Tao and Poo, 2005; Bestman and Cline, 2008; Bestman et al., 2008; Deeg et al., 2009; Pratt and Aizenman, 2009; Shen et al., 2011, 2014).

One mechanism that may facilitate $\mathrm{T}_{3}$-induced dendritic growth is a change in activity of the small GTPases, including RhoA (Van Aelst and Cline, 2004). Our qPCR data show that $n$ rep expression increased nearly sixfold within $2 \mathrm{~d}$ of $\mathrm{T}_{3}$ treatment, consistent with previous results (Das et al., 2006). nrep is ubiquitously and highly expressed during the late stages of fetal brain development in mice and decreases postnatally except in the cerebellum, hippocampus, and subventricular zone, all areas where cell proliferation persists after birth (Studler et al., 1993). NREP promotes neurite outgrowth in PC12 cells and in cultured rodent hippocampal neurons by a mechanism that is blocked by activation of Rho kinase, a downstream effector of RhoA (Fujitani et al., 2004). Timelapse in vivo imaging studies indicate that Xenopus tectal cell dendritic arbors elaborate by decreasing RhoA activity and increasing Rac1 and cdc42 activity downstream of visually driven glutamatergic activity (Li et al., 2000, 2002; Sin et al., 2002). Together, these data suggest that a $T_{3}$-induced increase in NREP may contribute to tectal neuron dendritic arborization by decreasing Rho kinase activity and modulating cytoskeletal rearrangements downstream of glutamatergic synaptic input (Van Aelst and Cline, 2004). A similar mechanism may operate in Purkinje cells; RhoA and Racl are highly expressed in Purkinje cells in fetal brain, but RhoA expression in Purkinje cells decreases postnatally (Richard et al., 2008), correlating with increased dendritic arbor elaboration.

The spatial and temporal control of $\mathrm{TH}$ signaling during brain development is tightly regulated by changes in expression of TRs, deiodinases, and TH transporters (Chatonnet et al., 2011; Peeters et al., 2013). DIO3 is highly expressed in neurogenic regions of the tadpole midbrain (Morvan Dubois et al., 2006) and at early stages of mammalian brain development (Chatonnet et al., 2011). Furthermore, DIO3 expression is homeostatically regulated by $\mathrm{T}_{3}$, such that high $\mathrm{T}_{3}$ increases DIO3 expression, which effectively decreases local $\mathrm{T}_{3}$ levels (Chatonnet et al., 2011). We show that TH acts locally in the 
midbrain to increase tectal NPC proliferation, neuronal differentiation, and dendritic arbor elaboration. $\mathrm{T}_{3} \mathrm{CO}$ injected into the midbrain ventricle increased proliferation locally but did not affect the eye, and vice versa. Moreover, electroporating DIO3 morpholinos into the tectum increased tectal cell proliferation. Conversely, the goitrogen MMI reduced tectal cell proliferation by decreasing circulating $\mathrm{T}_{4}$. Our observation that tectal DIO3 knockdown reverses the effects of $5 \mathrm{~d}$ MMI treatment indicates that local DIO3 knockdown increased tectal $\mathrm{T}_{3}$ levels sufficiently to affect NPC fate, despite systemic MMI-dependent decreased $\mathrm{T}_{4}$ levels. This combination of treatments demonstrates the potency of DIO3 in regulating local TH signaling. By contrast, stage 41 tadpoles (2-3 $\mathrm{d}$ younger than tadpoles our experiments) treated with $\mathrm{TH}$ do not exhibit increased neural cell proliferation, even though chemically blocking TH signaling at these stages decreased proliferation (Fini et al., 2012). These experiments emphasize the dynamic regulation of $\mathrm{TH}$ signaling in the brain. High DIO3 expression during embryonic and premetamorphic tadpole stages (Morvan Dubois et al., 2006; Tindall et al., 2007) indicates that $\mathrm{TH}$ signaling is tempered during early brain development, as previously noted in mammalian development (Chatonnet et al., 2011). These results indicate that homeostatic control of local $\mathrm{T}_{3}$ action within the optic tectum normally maintains tectal cell neurogenesis within certain tolerances. Although DIO3 expression is regulated by $\mathrm{T}_{3}$ levels (Mann and Holt, 2001; Chatonnet et al., 2011), the identity of feedback signals that trigger homeostatic control of cell proliferation remains an important open question.

In conclusion, we demonstrated that local $\mathrm{TH}$ signaling affects brain development at tadpole stages when animals must establish neural circuits necessary to forage for food and avoid predators. Using spatial and temporal control over $\mathrm{TH}$ signaling components, including targeted delivery of DIO3 morpholinos to the tectum and local delivery of $\mathrm{T}_{3}$ in coconut oil, combined with time-lapse in vivo imaging to identify distinct responses to $\mathrm{T}_{3}$ in NPCs and neurons over the $\mathrm{T}_{3}$ exposure time, we show that $\mathrm{TH}$ signaling regulates neural cell proliferation and differentiation and, separately, that $\mathrm{T}_{3}$ induces a large-scale increase in structural complexity in neuronal dendritic arbors that had already reached a growth plateau. These data indicate that local exposure of the optic tectum to $\mathrm{T}_{3}$ mediates distinct effects in target cells at different points in the life of NPCs and neurons.

\section{References}

Akerman CJ, Cline HT (2006) Depolarizing GABAergic conductances regulate the balance of excitation to inhibition in the developing retinotectal circuit in vivo. J Neurosci 26:5117-5130. CrossRef Medline

Allen BM (1924) Brain development in anuran larvae after thyroid or pituitary gland removal. Endocrinology 8:639-651. CrossRef

Anderson GW (2001) Thyroid hormones and the brain. Front Neuroendocrinol 22:1-17. CrossRef Medline

Bernal J (2007) Thyroid hormone receptors in brain development and function. Nat Clin Pract Endocrinol Metab 3:249-259. CrossRef Medline

Bestman J, Santos da Silva J, Cline HT (2008) Dendrite development. In: Dendrites (Stuart G, Spruston N, Hausser M, eds), pp 69-94. Oxford: Oxford UP.

Bestman JE, Cline HT (2008) The RNA binding protein CPEB regulates dendrite morphogenesis and neuronal circuit assembly in vivo. Proc Natl Acad Sci U S A 105:20494-20499. CrossRef Medline

Bestman JE, Cline HT (2014) Morpholino studies in Xenopus brain development. Methods Mol Biol 1082:155-171. CrossRef Medline

Bestman JE, Lee-Osbourne J, Cline HT (2012) In vivo time-lapse imaging of cell proliferation and differentiation in the optic tectum of Xenopus laevis tadpoles. J Comp Neurol 520:401-433. CrossRef Medline

Bestman JE, Huang LC, Lee-Osbourne J, Cheung P, Cline HT (2015) An in vivo screen to identify candidate neurogenic genes in the developing Xenopus visual system. Dev Biol 408:269-291. CrossRef Medline

Cantallops I, Haas K, Cline HT (2000) Postsynaptic CPG15 promotes synaptic maturation and presynaptic axon arbor elaboration in vivo. Nat Neurosci 3:1004-1011. CrossRef Medline

Chatonnet F, Picou F, Fauquier T, Flamant F (2011) Thyroid hormone action in cerebellum and cerebral cortex development. J Thyroid Res 2011: 145762. CrossRef Medline

Chiu SL, Chen CM, Cline HT (2008) Insulin receptor signaling regulates synapse number, dendritic plasticity, and circuit function in vivo. Neuron 58:708-719. CrossRef Medline

Choi J, Suzuki KT, Sakuma T, Shewade L, Yamamoto T, Buchholz DR (2015) Unliganded thyroid hormone receptor alpha regulates developmental timing via gene repression in Xenopus tropicalis. Endocrinology 156: 735-744. CrossRef Medline

Coen L, Le Blay K, Rowe I, Demeneix BA (2007) Caspase-9 regulates apoptosis/proliferation balance during metamorphic brain remodeling in Xenopus. Proc Natl Acad Sci U S A 104:8502-8507. CrossRef Medline

Das B, Cai L, Carter MG, Piao YL, Sharov AA, Ko MS, Brown DD (2006) Gene expression changes at metamorphosis induced by thyroid hormone in Xenopus laevis tadpoles. Dev Biol 291:342-355. CrossRef Medline

Deeg KE, Sears IB, Aizenman CD (2009) Development of multisensory convergence in the Xenopus optic tectum. J Neurophysiol 102:3392-3404. CrossRef Medline

Denver RJ (1998) The molecular basis of thyroid hormone-dependent central nervous system remodeling during amphibian metamorphosis. Comp Biochem Physiol C 119:219-228. Medline

Denver RJ, Pavgi S, Shi YB (1997) Thyroid hormone-dependent gene expression program for Xenopus neural development. J Biol Chem 272: 8179-8188. CrossRef Medline

Denver RJ, Ouellet L, Furling D, Kobayashi A, Fujii-Kuriyama Y, Puymirat J (1999) Basic transcription element-binding protein (BTEB) is a thyroid hormone-regulated gene in the developing central nervous system-evidence for a role in neurite outgrowth. J Biol Chem 274:23128-23134. CrossRef Medline

Denver RJ, Hu F, Scanlan TS, Furlow JD (2009) Thyroid hormone receptor subtype specificity for hormone-dependent neurogenesis in Xenopus laevis. Dev Biol 326:155-168. CrossRef Medline

Duarte-Guterman P, Trudeau VL (2010) Regulation of thyroid hormone-, oestrogen- and androgen-related genes by triiodothyronine in the brain of Silurana tropicalis. J Neuroendocrinol 22:1023-1031. CrossRef Medline

Eayrs JT (1955) The cerebral cortex of normal and hypothyroid rats. Acta Anat 25:160-183. CrossRef Medline

Eayrs JT, Taylor SH (1951) The effect of thyroid deficiency induced by methyl thiouracil on the maturation of the central nervous system. J Anat 85:350-358. Medline

Faulkner RL, Wishard TJ, Thompson CK, Liu HH, Cline HT (2015) FMRP regulates neurogenesis in tadpoles. Eneuro 2:e0055. CrossRef Medline

Fini JB, Le Mével S, Palmier K, Darras VM, Punzon I, Richardson SJ, ClergetFroidevaux MS, Demeneix BA (2012) Thyroid hormone signaling in the Xenopus laevis embryo is functional and susceptible to endocrine disruption. Endocrinology 153:5068-5081. CrossRef Medline

Fujitani M, Yamagishi S, Che YH, Hata K, Kubo T, Ino H, Tohyama M, Yamashita T (2004) P311 accelerates nerve regeneration of the axotomized facial nerve. J Neurochem 91:737-744. CrossRef Medline

Gona AG, Uray NJ, Hauser KF (1988) Developmental neurobiology of the frog: proceedings of a symposium in honor of Jerry J. Kollros, held in New Orleans, Louisiana, December 27-30, 1987. New York: Liss.

Gudernatsch JF (1912) Feeding experiments on tadpoles. I. The influence of specific organs given as food on growth and differentiation. A contribution to the knowledge of organs with internal secretion. Arch Entwicklung Org 35:457-483. CrossRef

Haas K, Li J, Cline HT (2006) AMPA receptors regulate experiencedependent dendritic arbor growth in vivo. Proc Natl Acad Sci U S A 103: 12127-12131. CrossRef Medline

Havis E, Le Mevel S, Morvan Dubois G, Shi DL, Scanlan TS, Demeneix BA, Sachs LM (2006) Unliganded thyroid hormone receptor is essential for 
Xenopus laevis eye development. EMBO J 25:4943-4951. CrossRef Medline

Heuer H, Mason CA (2003) Thyroid hormone induces cerebellar Purkinje cell dendritic development via the thyroid hormone receptor $\alpha 1$. J Neurosci 23:10604-10612. Medline

He HY, Shen W, Hiramoto M, Cline HT (2016) Experience-dependent bimodal plasticity of inhibitory neurons in early development. Neuron 90: 1203-1214. CrossRef Medline

Hoskins SG, Grobstein P (1984) Induction of the ipsilateral retinothalamic projection in Xenopus laevis by thyroxine. Nature 307:730-733. CrossRef Medline

Hoskins SG, Grobstein P (1985a) Development of the ipsilateral retinothalamic projection in the frog Xenopus laevis. I. Retinal distribution of ipsilaterally projecting cells in normal and experimentally manipulated frogs. J Neurosci 5:911-919. Medline

Hoskins SG, Grobstein P (1985b) Development of the ipsilateral retinothalamic projection in the frog Xenopus laevis. III. The role of thyroxine. J Neurosci 5:930-940. Medline

Hughes A (1976) Metamorphic changes in the brain and spinal cord. In: Frog neurobiology: a handbook (Llinás RR, Precht W, eds), pp 856-863. Berlin-Heidelberg: Springer.

Kaltenbach JC (1970) Local metamorphic action of thyroxine analogues in Rana pipiens larvae. J Exp Zool 174:55-63. CrossRef Medline

Kaltenbach JC, Hobbs AW (1972) Local action of thyroxine on amphibian metamorphosis. V. Cell division in the eye of anuran larvae effected by thyroxine-cholesterol implants. J Exp Zool 179:157-166. CrossRef Medline

Kelley DB (1996) Sexual differentiation in Xenopus laevis. In: The biology of Xenopus (Tinsley R, Kobel H, eds), pp 143-176. Oxford: Oxford UP.

Koibuchi N (2013) The role of thyroid hormone on functional organization in the cerebellum. Cerebellum 12:304-306. CrossRef Medline

Kollros JJ (1981) Metamorphosis, a problem in developmental biology, Ed 2. New York: Plenum.

Kollros JJ, Thiesse ML (1985) Growth and death of cells of the mesencephalic fifth nucleus in Xenopus laevis larvae. J Comp Neurol 233:481489. CrossRef

Leatherland JF (1987) Thyroid response to ovine thyrotropin challenge in cortisol- and dexamethasone-treated rainbow trout, Salmo gairdneri. Comp Biochem Physiol A Comp Physiol 86:383-387. CrossRef Medline

Legrand J (1967) Analysis of the morphogenetic action of thyroid hormone on young rat cerebellum. Arch Anat Microsc Mo rph Exp 56:205-244.

Legrand J (1979) Morphogenetic actions of thyroid hormones. Trends Neurosci 2:234-236. CrossRef

Li J, Erisir A, Cline H (2011) In vivo time-lapse imaging and serial section electron microscopy reveal developmental synaptic rearrangements. Neuron 69:273-286. CrossRef Medline

Li Z, Van Aelst L, Cline HT (2000) Rho GTPases regulate distinct aspects of dendritic arbor growth in Xenopus central neurons in vivo. Nat Neurosci 3:217-225. CrossRef Medline

Li Z, Aizenman CD, Cline HT (2002) Regulation of rho GTPases by crosstalk and neuronal activity in vivo. Neuron 33:741-750. CrossRef Medline

Madeira MD, Cadete-Leite A, Andrade JP, Paula-Barbosa MM (1991) Effects of hypothyroidism upon the granular layer of the dentate gyrus in male and female-adult rats-a morphometric study. J Comp Neurol 314: 171-186. CrossRef Medline

Maga G, Hubscher U (2003) Proliferating cell nuclear antigen (PCNA): a dancer with many partners. J Cell Sci 116:3051-3060. CrossRef Medline

Mann F, Holt CE (2001) Control of retinal growth and axon divergence at the chiasm: lessons from Xenopus. Bioessays 23:319-326. CrossRef Medline

Marsh-Armstrong N, Huang H, Remo BF, Liu TT, Brown DD (1999) Asymmetric growth and development of the Xenopus laevis retina during metamorphosis is controlled by type III deiodinase. Neuron 24:871-878. CrossRef Medline

Martinez-Galan JR, Pedraza P, Santacana M, Escobar del Ray F, Morreale de Escobar G, Ruiz-Marcos A (1997) Early effects of iodine deficiency on radial glial cells of the hippocampus of the rat fetus. A model of neurological cretinism. J Clin Invest 99:2701-2709. CrossRef Medline

Martinez-Galan JR, del Rey FE, de Escobar GM, Santacana M, Ruiz-Marcos A (2004) Hypothyroidsm alters the development of radial glial cells in the term fetal and postnatal neocortex of the rat. Dev Brain Res 153:109-114. CrossRef
Mohan V, Sinha RA, Pathak A, Rastogi L, Kumar P, Pal A, Godbole MM (2012) Maternal thyroid hormone deficiency affects the fetal neocorticogenesis by reducing the proliferating pool, rate of neurogenesis and indirect neurogenesis. Exp Neurol 237:477-488. CrossRef Medline

Morvan Dubois G, Sebillot A, Kuiper GG, Verhoelst CH, Darras VM, Visser TJ, Demeneix BA (2006) Deiodinase activity is present in Xenopus laevis during early embryogenesis. Endocrinology 147:4941-4949. CrossRef Medline

Nedivi E, Wu GY, Cline HT (1998) Promotion of dendritic growth by CPG15, an activity-induced signaling molecule. Science 281:1863-1866. CrossRef Medline

Nicholson JL, Altman J (1972a) The effects of early hypo- and hyperthyroidism on the development of rat cerebellar cortex. I. Cell proliferation and differentiation. Brain Res 44:13-23. CrossRef Medline

Nicholson JL, Altman J (1972b) The effects of early hypo- and hyperthyroidism on the development of the rat cerebellar cortex. II. Synaptogenesis in the molecular layer. Brain Res 44:25-36. CrossRef Medline

Nicholson JL, Altman J (1972c) Synaptogenesis in the rat cerebellum: effects of early hypo- and hyperthyroidism. Science 176:530-532. CrossRef Medline

Niell CM, Meyer MP, Smith SJ (2004) In vivo imaging of synapse formation on a growing dendritic arbor. Nat Neurosci 7:254-260. CrossRef Medline

Nieuwkoop PD, Faber J (1956) Normal table of Xenopus laevis (Daudin): a systematical and chronological survey of the development from the fertilized egg till the end of metamorphosis. New York: Garland.

Oppenheimer JH, Schwartz HL (1997) Molecular basis of thyroid hormone-dependent brain development. Endocr Rev 18:462-475. CrossRef Medline

Peeters RP, Hernandez A, Ng L, Ma M, Sharlin DS, Pandey M, Simonds WF, St Germain DL, Forrest D (2013) Cerebellar abnormalities in mice lacking type 3 deiodinase and partial reversal of phenotype by deletion of thyroid hormone receptor alphal. Endocrinology 154:550-561. CrossRef Medline

Pratt KG, Aizenman CD (2009) Multisensory integration in mesencephalic trigeminal neurons in Xenopus tadpoles. J Neurophysiol 102:399-412. CrossRef Medline

Richard V, Dulon D, Hafidi A (2008) Expression of Rho GTPases Rho-A and Racl in the adult and developing gerbil cerebellum. Int J Dev Neurosci 26:723-732. CrossRef Medline

Ryu S, Driever W (2006) Minichromosome maintenance proteins as markers for proliferation zones during embryogenesis. Cell Cycle 5:11401142. CrossRef Medline

Sanchez AL, Matthews BJ, Meynard MM, Hu B, Javed S, Cohen Cory S (2006) BDNF increases synapse density in dendrites of developing tectal neurons in vivo. Development 133:2477-2486. CrossRef Medline

Sharma P, Cline HT (2010) Visual activity regulates neural progenitor cells in developing Xenopus CNS through Musashil. Neuron 68:442-455. CrossRef Medline

Shen W, Da Silva JS, He H, Cline HT (2009) Type A GABA-receptordependent synaptic transmission sculpts dendritic arbor structure in $\mathrm{Xe}$ nopus tadpoles in vivo. J Neurosci 29:5032-5043. CrossRef Medline

Shen W, McKeown CR, Demas JA, Cline HT (2011) Inhibition to excitation ratio regulates visual system responses and behavior in vivo. J Neurophysiol 106:2285-2302. CrossRef Medline

Shen W, Liu HH, Schiapparelli L, McClatchy D, He HY, Yates JR 3rd, Cline HT (2014) Acute synthesis of CPEB is required for plasticity of visual avoidance behavior in Xenopus. Cell Rep 6:737-747. CrossRef Medline

Shi Y-B (2000) Amphibian metamorphosis: from morphology to molecular biology. New York: Wiley.

Sin WC, Haas K, Ruthazer ES, Cline HT (2002) Dendrite growth increased by visual activity requires NMDA receptor and Rho GTPases. Nature 419:475-480. CrossRef Medline

Straznicky K, Gaze R (1972) The development of the tectum in Xenopus laevis: an autoradiographic study. J Embryol Exp Morphol 28:87-115. Medline

Studler JM, Glowinski J, Lévi-Strauss M (1993) An abundant mRNA of the embryonic brain persists at a high level in cerebellum, hippocampus and olfactory bulb during adulthood. Eur J Neurosci 5:614-623. CrossRef Medline

Tao HW, Poo MM (2005) Activity-dependent matching of excitatory and 
inhibitory inputs during refinement of visual receptive fields. Neuron 45:829-836. CrossRef Medline

Tata JR (1968) Early metamorphic competence of Xenopus larvae. Dev Biol 18:415-440. CrossRef Medline

Tindall AJ, Morris ID, Pownall ME, Isaacs HV (2007) Expression of enzymes involved in thyroid hormone metabolism during the early development of Xenopus tropicalis. Biol Cell 99:151-163. CrossRef Medline

Van Aelst L, Cline HT (2004) Rho GTPases and activity-dependent dendrite development. Curr Opin Neurobiol 14:297-304. CrossRef Medline

Wang Y, Wang Y, Dong J, Wei W, Song B, Min H, Teng W, Chen J (2014) Developmental hypothyroxinaemia and hypothyroidism limit dendritic growth of cerebellar Purkinje cells in rat offspring: involvement of microtubule-associated protein 2 (MAP2) and stathmin. Neuropathol Appl Neurobiol 40:398-415. CrossRef Medline

Wen L, Shi YB (2015) Unliganded thyroid hormone receptor alpha controls developmental timing in Xenopus tropicalis. Endocrinology 156:721734. CrossRef Medline

Wu G, Malinow R, Cline HT (1996) Maturation of a central glutamatergic synapse. Science 274:972-976. CrossRef Medline

Wu GY, Cline HT (1998) Stabilization of dendritic arbor structure in vivo by CaMKII. Science 279:222-226. CrossRef Medline

Zoeller RT, Rovet J (2004) Timing of thyroid hormone action in the developing brain: clinical observations and experimental findings. J Neuroendocrinol 16:809-818. CrossRef Medline 